\title{
MATRIMONIO, CONSANGUINIDAD Y LA ARISTOCRACIA NUEVA CASTELLANA: CONSOLIDACIÓN DE LA Casa de Alba (1440-1531)*
}

\author{
JuAN HERNÁNDEZ FranCo \\ Universidad de Murcia
}

Recibido: 16 de octubre de 2017

Aceptado: 23 de noviembre de 2017

\section{Resumen}

Historia Social, Historia de la Familia e Historia Política convergen en el presente artículo para intentar analizar cómo se forma la casa de Alba, y avanzar en su trayectoria de ascenso social desde el siglo XIII, cuando son miembros de la oligarquía toledana, hasta 1531, inicios del periodo del ducado de Fernando Álvarez de Toledo, el Grande. En ese proceso desempeña un destacado papel las alianzas matrimoniales con casas aristocráticas de más lustre (Enríquez y Benavente) y con posterioridad, especialmente en el siglo XVI, la recurrencia a matrimonios entre parientes muy cercanos en grado de consanguinidad.

\section{Palabras clave}

Nobleza; historia social; historia de la familia; siglos XV-XVI.

\begin{abstract}
Social History, Family History and Political History converge on this article, in which we try to analyse how the house of Alba was formed, and progress in the trajectory of social ascent the house of Alba experienced from the 13th century -when they were members of the oligarchy of Toledountil 1531, when the Duchy was created for Fernando Álvarez de Toledo, the Great. In this process, marital alliances with more prestigious aristocratic families, such as the Enríquez and the Benavente, played a prominent role, and subsequently, in the sixteenth century, marriages between close relatives with some degree of consanguinity became recurrent.
\end{abstract}

\section{Keywords}

Nobility; social history; family history; $15^{\text {th }}-16^{\text {th }}$ centuries.

\section{Sommario}

Storia Sociale, Storia della Famiglia e Storia Politica convergono nel presente saggio per analizzare come si forma la casa nobile di Alba e avanzare nella sua traiettoria di promozione sociale dal secolo

* El presente trabajo forma parte del proyecto de investigación HAR2017-84226-C6-1-P, financiado por el Ministerio de Economía y Competitividad del Gobierno de España. Correo electrónico: jhf@um.es. ORCID: http://orcid.org/0000-0001-7370-0313. 
XIII, quando sono membri dell'oligarchia di Toledo, fino al 1531, all'inizio del periodo del ducato di Fernando Álvarez de Toledo, el Grande. Alleanze matrimoniale con altre case aristocratiche di maggior splendore (Enríquez e Benavente) e in seguito, soprattutto nel secolo XVI, la ricorrenza dei matrimoni tra parenti stretti nel grado di consanguineità svolge un ruolo importante in questo processo.

\section{Parole chiave}

Nobiltà; storia sociale; storia familiare; secoli XV-XVI.

Indica G. Delille que consanguinidad y matrimonio ocupan un lugar central en la constitución de relaciones sociales y políticas en los últimos siglos de la edad media y durante los siglos modernos ${ }^{1}$. Por su parte, D. Sabean, tras mostrarnos -en un seminal trabajo publicado el año 1998 relativo a la utilidad analítica del "parentesco"- como a finales del siglo XVIII y el XIX se recurre con frecuencia por parte de las familias nucleares a la consanguinidad, es decir que al producirse la transición hacia sociedad industrial, siguen teniendo relevancia las relaciones entre parientes y alcanzan un importante papel en la formación de matrimonios ${ }^{2}$, en posteriores trabajos ha indicado que también se recurre a los matrimonios consanguíneos a lo largo de la baja edad media y la moderna por parte de las familias que tienen o bien ansían el poder; su uso, por tanto, está generalizado en la esfera de las relaciones de poder, lo que implica que se produzca una regulación y control de estas prácticas por parte de un "Estado en proceso de formación"3. Precisamente siguiendo las propuestas de ambos historiadores, nuestro objetivo es, igualmente, mostrar como matrimonio y consanguinidad desempeñan -junto a la política- un destacado papel en la constitución y, sobre todo, en la consolidación a lo largo de los siglos XV y XVI de la "nobleza nueva" que habían creado los Trastámaras. Al respecto, la casa de Alba de Tormes, la rama más importante del linaje Álvarez de Toledo, es una de las exponentes más cualificadas de la gran aristocracia territorial, que mediante alianzas matrimoniales con casas de superior o similar distinción social y la continuidad de esas relaciones en los márgenes que permiten los grados de consanguinidad, unido al servicio a los monarcas, tras otorgarle la monarquía castellana la consideración de Grandes en el siglo $\mathrm{XV}^{4}$, finalmente en el siglo XVI, forman parte del reducido número de casas que integran la Grandeza de la Monarquía Hispánica.

La principal fuente -aunque no única- con la que realizaremos el presente trabajo, recoge, aunque sin establecer relación estricta, precisas referencias a matrimonios, grados de consanguinidad y mercedes políticas y sociales concedidas por los monarcas Trastámaras

\footnotetext{
DeLILLE, El alcalde y el cura: poder central y poder local en el mediterráneo occidental, siglos XVXVIII, passim.

2 Sabean, Kinship in Neckarhausen, 1700-1870, passim.

3 Sabean, Teuscher and Mathieu (edt), Kinship in Europe: Approaches to Long-Term Development (1300-1900); y Johnson, Sabean, Teuscher and Trivellato, Transregional and Transnacional Families in Europe and Beyond. Experiences since the Middle Ages, pp. 1-21.

4 Quintanilla Raso, "El engrandecimiento nobiliario en la Corona de Castilla. Las claves del proceso a finales de la Edad Media", p. 90.
} 
y Habsburgos a los Alba. Se trata de un manuscrito, fechado el año 1757 e intitulado "Explicación del Árbol Genealógico de los Señores de esta Cassa [Alba], con sus Casamientos, y Empleos que obtuvieron, con cita de Instrumentos"s. Su autor es el archivero de la casa ducal de Alba, Juan José Jimeno, que como ha indicado recientemente Ortega Calderón, lleva a cabo la labor de modernización del archivo ducal a lo largo de los años centrales del siglo XVIII ${ }^{6}$. Y entre cuyos trabajos como archivero, sobresale este manuscrito de doscientos treinta y ocho folios. Los primeros testimonios documentales que recoge el archivero son del año 1229. Sin embargo, no es hasta iniciado el siglo XIV, con los datos que en el archivo ducal se poseen sobre Garci Álvarez, alcalde mayor de Toledo, cuando realmente la información comienza a ser abundante y fiable. A partir de 1326, Jimeno va señalando matrimonios, empleos, concesión de títulos nobiliarios, fundación de mayorazgos...realizados o conseguidos por las sucesivas generaciones de la rama más destacada del linaje de los Álvarez de Toledo hasta llegar al duodécimo Duque de Alba, Fernando Silva Álvarez de Toledo Haro (1714-1776).

Dentro de esta documentada historia de la casa de Alba, Jimeno pone especial énfasis en los matrimonios y señala con absoluta precisión el grado de consanguinidad entre los contrayentes, indicando los documentos en los que se encuentran las dispensas papales y las capitulaciones -actualmente, en su mayoría, desaparecidas-. Pero su acertado tino documental, no debe hacernos suponer que la cuestión que planteamos como arco de bóveda: matrimonio-consanguinidad-política, nos la resuelva el archivero. Jimeno informa sobre los matrimonios contraídos por los miembros de la casas, especialmente los primogénitos, la petición de dispensa de consanguinidad, y los méritos que reúnen las diversas generaciones de Álvarez de Toledo-casa de Alba para ser recompensados desde 1355 y con mayores creces a partir de 1470 por los monarcas con oficios, mercedes, y algo de tanto valor en un mundo de símbolos ${ }^{7}$ como es el favor regio. Pero, como es lógico, el archivero Jimeno no sugiere que las relaciones constituidas a través del matrimonio son un instrumento directo para conseguir metas sociales y políticas; prestigio, influencia y dominio a la postre. En todo caso, esa es la cuestión que corresponde al historiador: examinar y analizar hasta qué punto los objetivos de familias aristocráticas orientados hacia la máxima distinción social y el relieve político dan pie a alianzas matrimoniales, y si estas se realizan o no en un contexto de consanguinidad y de homogamia social, hechos a los que no es ajena la Monarquía, coincidiendo con un periodo (siglos XV-XVI) en que cada vez es mayor su control sobre la aristocracia.

\footnotetext{
Archivo de los Duques de Alba (ADA), Caja (c.) 128, nº 24. El manuscrito original, según nos indica el propio Juan José Jimeno, está fechado en Madrid, 14 de octubre de 1756. Del mismo se hace un traslado al manuscrito consultado, que está datado en Madrid, 20-I-1757.

6 Calderón Ortega, "Memoria familiar e historia de la memoria: el archivo de la Casa de Alba", pp. 177-202; y "El archivo de la casa de Alba", pp. 79-100.

7 Quintanilla Raso, "La nobleza en la historia política castellana en la segunda mitad del siglo XV. Bases de poder y pautas de comportamiento", pp. 181-200; y Palencia Herrejón, "Elementos simbólicos del poder de la nobleza urbana en Castilla: los Ayala de Toledo al final del Medievo", pp. 163-180.
} 


\section{El “árbol” o la raíz y tronco del linaje Álvarez de Toledo}

Una de las más destacadas historiadoras de la familia como es C. Klapisch-Zuber, tras sus consagrados trabajos sobre las familias toscanas en el cuatrocientos, el año 2000 publica un brillante libro sobre las razones por las que a finales del siglo XV y principios del XVI, el árbol familiar se convierte en la imagen empleada para representar las relaciones familiares a lo largo del tiempo. El árbol se transforma en una conciencia familiar -inicialmente de las dinastías y luego de los linajes altonobiliarios-que permite mostrar los orígenes familiares y poner de manifiesto al resto de la sociedad la vinculación con ancestros míticos, bíblicos o históricos; las proezas y los triunfos conseguidos a lo largo de generaciones, así como la calidad o «raza» que atesora el linaje ${ }^{8}$.

Si seguimos lo expuesto por la historiadora francesa, no puede sorprendernos que entre mediados del siglo XV y hasta bien entrado el siglo XVIII tenga lugar la edad dorada de los libros genealógicos en Castilla ${ }^{9}$. Si tuviéramos que escoger autores representativos, podríamos citar desde quien los escriben en el siglo XV como Juan Rodríguez de la Cámara, Ferrán Mexía, Juan de Lucena, Pedro Gracia Dei, Diego Hernández de Mendoza ${ }^{10}$....hasta quienes los hacen en el setecientos, como Juan Félix Francisco Rivarola, Sebastián del Castillo Ruiz de Molina, Juan Baptista Gómez, José Berni y Catalá, y Manuel Treyes ${ }^{11}$.

Fijémonos, antes de volver a los Álvarez de Toledo y en concreto al Árbol que levanta Jimeno como expresión de la distinción conseguida por la casa de Alba, en lo que dice el gran tratadista emeritense Bernabé Moreno de Vargas respecto a las metáforas que llevan implícitas los árboles. El ser biológico en el que se transforma el árbol acoge toda la virtud que posee el linaje nobiliario y es capaz de representarla perfectamente, pues «siendo las raizes, y el tronco del árbol bueno, no pueden dejar de ser buenos los frutos» ${ }^{12}$ La fuerza de esta idea, desde luego está presente en Jimeno, que busca la raíz de la familia, para ir presentando minuciosamente las obras y méritos que cada generación de Álvarez de Toledo-casa de Alba, especialmente las que el «pariente mayor» deja y transmite a su linaje. Pero con la diferencia en el caso de Jimeno, que en la búsqueda del origen de la casa de Alba, lo que podríamos llamar generaciones increíbles ${ }^{13}$, son desechadas. Prefiere la seguridad o posible veracidad que ofrecen los documentos guardados en el archivo familiar.

\footnotetext{
Klapisch-Zuber, L'ombre des ancêtres: essai sur l'imaginaire médiéval de la parenté.

9 Guillén Berrendero, La edad de la nobleza: identidad nobiliaria en Castilla y Portugal (1556-1621), pp. 27-147.

10 Valverde Ogallar, Manuscritos y heráldica en el tránsito a la modernidad: el libro de armería de Diego Hernández de Mendoza; Carlos Heusch, "Le chevalier Ferrán Mexía et son Nobiliario vero (1492): de l'imaginaire chevaleresque à la logique de l'exclusion", y MARTín Romero, "El origen de la nobleza según el Nobiliario vero de Hernán Mexía”, pp. 1-23.

11 Hernández Franco, "Libros de genealogías y reflexiones desde la historia social sobre los linajes castellanos en la Edad Moderna", pp. 341-354

12 Moreno de Vargas, Discursos de la nobleza de España, p. 40.

13 Bızzochi, Genealogie incredibile. Scritti di storia nell'Europa moderna.
} 
Decimos esto, pues aunque la casa de Alba es una de la que menos recurre a genealogistas y reyes de armas para engrandecer su pasado, cuando tal hecho ocurre, se aprecia claramente la escrupulosidad y esmero de los datos sobre el linaje que aporta Jimeno, aunque ello supone no poder remontarse a un mítico ancestro. Circunstancia, por cierto, totalmente distinta a como tratan los genealogistas la antigüedad y méritos de la casa de Oropesa, rama que al igual que Alba proviene del linaje de los Álvarez de Toledo.

El linajista de la casa de Oropesa: Francisco Herrera Maldonado, en la disertación que escribe el año 1621 sobre los orígenes y descendencia de los Toledo, no duda en recurrir a una construcción discursiva de naturaleza apologética y legitimista ${ }^{14}$, presentándonos un origen o raíz, y un tronco de los Álvarez de Toledo, que contrasta con la raíz desnuda y sencilla que un siglo y medio después presenta Jimeno. Es cierto que Herrera Maldonado no cae en el vicio -en su opinión- de buscarles una génesis proveniente de una destaca dinastía foránea -según dice, algunos se la habían encontrado en los Paleólogos «Emperadores de Grecia»-, ni en la nobleza extranjera. Para Herrera, que defiende el origen godo de la nobleza hispana ${ }^{15}$, como venía ocurriendo entre una parte de los tratadistas desde mediados del siglo XV -influenciados por Alfonso García de Santa María y Rodrigo Sánchez de Arévalo- el primer origen del tronco de los "Toledo de España" se encuentra «con prouabilidad, y certeza » en el distinguido rico hombre Pedro Alvar Yáñez, hermano del Conde Alvar Fañez o Fernández Minaya ${ }^{16}$, uno de los conquistadores de Toledo y destacado defensor de la frontera toledana tras la conquista de la ciudad el año 1085. Sus padres: Fernán Laynez y Jimena Núñez, coincidiendo con lo que en sus estudios han señalado Menéndez Pidal y Luis Rubio, y mucho más recientemente Margarita Torres ${ }^{17}$ y Placido Ballesteros San José ${ }^{18}$, eran parientes - «primos dos veces»-- del Cid Ruiz Díaz de Vivar. Pero no solo son parientes de uno de los grandes héroes de la leyenda gótica ${ }^{19}$, sino que Herrera emplea el linaje de los padres de Pedro Alvar Yáñez con el fin de establecer relación de parentesco bilateral (Laynez y Núñez) entre el linaje de los Toledo y los legendarios fundadores de Castilla: los jueces Laín Calvo y Nuño Rasura ${ }^{20}$-magistrados concebidos como eslabones originarios de la cadena soberanista castellana que tomaría cuerpo definitivo con los condes de la dinastía de Fernán González-, es decir con los personajes y acontecimientos de la más vieja y mitificada historia de Castilla. Posiblemente, muy posiblemente falsa, como dice Peña

\footnotetext{
14 Beceiro Pita, "La conciencia de los antepasados y la gloria del linaje en la Castilla bajomedieval", pp. 329-350; y "La legitimación del linaje a través de los ancestros", pp. 77-100.

15 GonzÁlez SÁnchez, "El mito gótico como configurador de la nación española", pp. 128-141 y "El mito gótico y la utopía de España", pp. 179-96; Villa Prieto, "La escritura de la Historia en la Baja Edad Media: deseo racional vs. propaganda política. La mentalidad de los cronistas", pp. 65-84.

16 Molina y Herrera Maldonado, Breue tratado de las virtudes de don Iuan Garcia Aluarez de Toledo, Monroy, Madrid, 1621, sin paginar.

17 Torres, "El linaje del Cid", pp. 6-49.

18 Ballesteros San José, Álvar Fáñez. Trayectoria histórica del defensor del reino de Toledo (1085-1114).

19 PeÑa Pérez, El surgimiento de una nación. Castilla en su historia y en sus mitos.

20 Martin, Les jueges de Castille. Mentalités et discours historiques dans l'Espagne médievale. Igualmente interesante para justificar el origen familiar, BeCEIRo PITA, "La legitimación del linaje...", pp. 77-100; y Aurel, "Memoria dinástica y mitos fundadores: la construcción social del pasado en la Edad Media", pp. 303-334.
} 
Pérez, pero elaborada para ser considerada por generaciones posteriores como verdadera y cierta ${ }^{21}$; ardid, por cierto, repetido por otras importantes casas bajomedievales para afianzar su antigüedad y prestigio -en concreto por Frías ${ }^{22}$.

En el árbol genealógico de Herrera, hasta llegar a la escisión del linaje Álvarez de Toledo en dos ramas a mediados del siglo XIV, origen a su vez de las futuras casas de Alba y Oropesa, nos encontramos con doce generaciones, probablemente inventadas algunas de ellas, con el fin de darle continuidad y firmeza a la casa de los condes de Oropesa. Por tanto, como veremos a continuación, muchas más generaciones que las expuestas por Jimeno para la casa de Alba en "Explicación del Árbol Genealógico...". Aunque debe indicarse que las generaciones propuestas por Herrera Maldonado, se encuentran bien apoyadas en hechos históricos -especialmente servicios a los reyes castellanos y participación en la conflictivas relaciones entre estos y sus nobles-, por lo que no es adecuado afirmar que toda su genealogía sea una fabulación. Además no se puede poner en duda que en el siglo XV la casa de Oropesa es una de las grandes casas aristocráticas, especialmente desde que en 1475 la reina Isabel concede el título condal a Fernando Álvarez de Toledo, por entonces uno de los pocos nobles que forma parte del reducido círculo de ricos hombres que hay en Castilla y señor de importantes posesiones en Toledo y en la Alta Extremadura ${ }^{23}$. Pero lo que nunca nos dirá Herrera es que Fernando era descendiente de un hijo natural del maestre García Álvarez de Toledo (fallecido el año 1370), pariente mayor de los Álvarez de Toledo, políticamente próximo en principio a Pedro I y con posterioridad a Enrique II, y I señor de Valdecorneja y Oropesa desde 1366.

Conocemos esta realidad por Jimeno. El archivero hace un notable esfuerzo por buscar el verdadero origen de los Álvarez de Toledo antes de escindirse en las ya indicadas casas. Y, como hemos indicado, prefiere presentar un árbol de raíz sencilla, que va aumentando generacionalmente su distinción merced a los méritos de sus sucesivos parientes mayores. Para Jimeno el punto de arranque es mucho más tardío que para Herrera, y desde luego no tiene el vetusto y distinguido origen que éste le asigna. El fundador del linaje de la casa de Alba no es un personaje mítico, ni se remonta en el tiempo tanto como hace Herrera para exaltar el origen de la casa de Oropesa y conseguir que emparienten con los linajes que fundan Castilla. Los Álvarez de Toledo, futuros duques de Alba, tienen su principio en el siglo XIII. El primer pariente mayor es un caballero y destacado oficial municipal de Toledo, Esteban de Illán, alcalde mayor:

\footnotetext{
${ }^{21}$ Peña Pérez, "Nuño Rasura y Laín Calvo: los orígenes del pensamiento mítico sobre Castilla”, pp. 33-65.

22 Jular Pérez-Alfaro, "Porque tengo obligación: genealogía, escritura e identidad nobiliarias. Los Velasco", pp. 307-330; y "La importancia de ser antiguo. Los Velasco y su construcción genealógica", pp. 201-236. Igualmente Moreno Ollero, Los dominios señoriales de la casa de Velasco en la baja edad media, pp. 85-151.

23 Moxó, Los antiguos señoríos de Toledo, pp. 53-67; y Franco Silva, "Oropesa. El nacimiento del señorío toledano a fines del siglo XIV", pp. 299-314.
} 

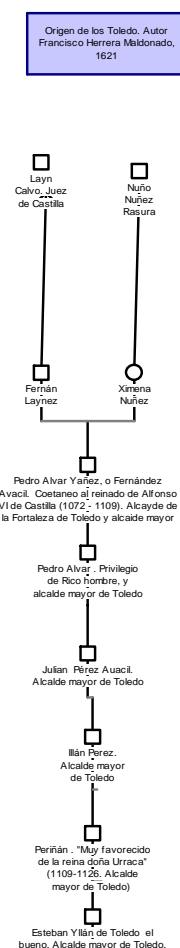

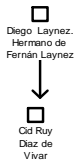

Genealogía 1. Árbol genealógico de los Álvarez de Toledo propuestos por Francisco Maldonado de Herrera (1621) y Juan José Jimeno (1757). Véase página 48.

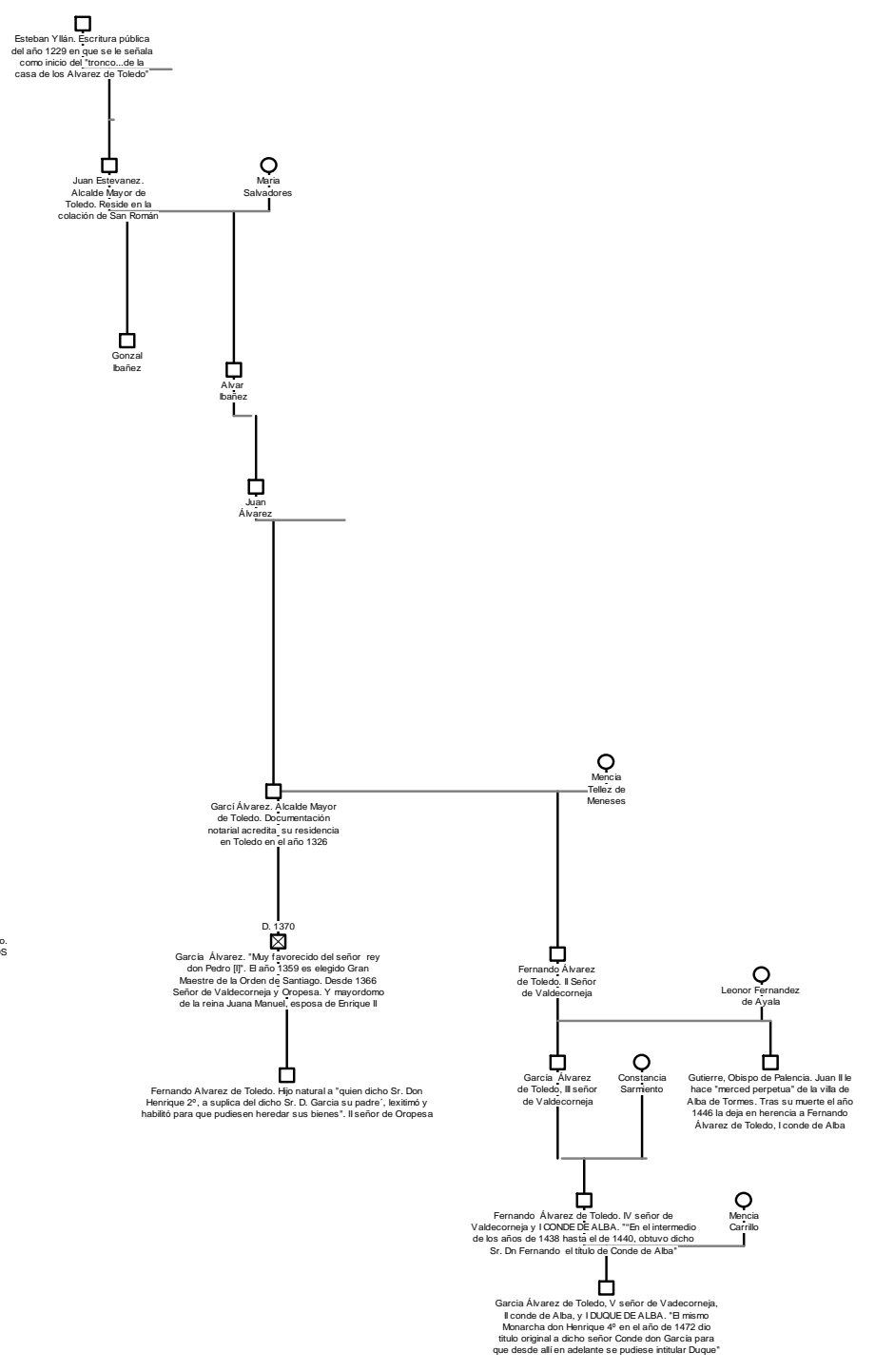


"Por una escriptura otorgada en Toledo en 10 de Noviembre Era de 1267, que es año de 1229, se reconoce que el tronco de la $\mathrm{Ex}^{\mathrm{ma}}$ Casa de los Alvarez de Toledo fue $\mathrm{D}^{\mathrm{n}}$ Estevan Illan Alcalde mayor de la dicha ciudad, no ay noticia del nombre de su mujer, ni de los empleos que tuvo"24.

El árbol de los Álvarez de Toledo, ulterior casa ducal de Alba, como nos muestra Jimeno se erige a partir de un destacado miembro de la oligarquía toledana y en ese entorno (de hecho residen en la colación de San Román, ocupada por el patriciado) permanecen por lo menos tres generaciones más -hasta la segunda mitad del siglo XIV-. Va a ser con el Maestre de la Orden de Santiago: García Álvarez, y desde abril de 1366 señor de Valdecorneja y Oropesa ${ }^{25}$, cuando comience verdaderamente el "brillante ascenso" de este linaje urbano y su transformación en miembros de la "nobleza nueva" de Castilla, aprovechando los cambios habidos en el estamento nobiliario tras la guerra civil entre Pedro I y su hermano Enrique. Por tanto, el análisis que nosotros podemos hacer del árbol de Jimeno coincide en buena medida con lo que acertadamente ha señalado Salvador de Moxó, relativo a que Garci Álvarez II, o el maestre García Álvarez como lo nomina Jimeno, es quien sienta las bases de las futuras casas de Alba y Oropesa, partes destacadas de la jerarquía nobiliaria castellana ${ }^{26}$.

Sigamos -ya exclusivamente con la información aportada por Jimeno- completando el árbol de la rama de los Álvarez de Toledo-Alba. Lo continuará Fernando, hermano del maestre. Pero es interesante saber cómo el maestre reparte su herencia, especialmente sus señoríos. De su matrimonio con Estefanía Pérez de Monroy -hija de Fernando Pérez de Monroy, II señor de Monroy- no tuvo descendencia. En cambio fuera del matrimonio, con María Petriel (sic), soltera, hija de Juan García de Loaysa, III señor de Petrel, engendra a Fernando Álvarez de Toledo; y con María Álvarez Mera, igualmente fuera del matrimonio, tiene otros dos hijos: Pedro y Mencía. Los tres hijos habidos fuera del matrimonio legal, tras petición de su padre, son legitimados por Enrique II para heredar parte de los bienes paternos ${ }^{27}$.

\footnotetext{
24 ADA, C. 128 , f. 3.

25 ADA, C. 128, fs. 7-9. Jimeno añade a la Real Cédula y sobrecarta de concesión del señorío de Valdecorneja, otorgada en Burgos, 16-XI-1366, la confirmación del mismo mediante un privilegio rodado dado por Enrique II, Toledo, 8-VI-1369. El preciso análisis de la concesión de este señorío y el de Oropesa, como recompensa por la renuncia al maestrazgo de Santiago, puede verse en Salvador de Moxó, "Los señoríos. En torno a una problemática para el estudio del régimen señorial”, pp. 400-404. Igualmente es imprescindible para comprender la creación del estado señorial de Alba, la excelente obra de CALDERÓN Ortega, El ducado de Alba. La evolución histórica, el gobierno y la hacienda de un estado señorial (siglos XIV-XVI), pp. 43-110, y 151-186.

26 Moxó, "El auge de la nobleza urbana en Castilla y su proyección en el ámbito administrativo y rural a comienzos de la Baja Edad Media", pp. 483-486.

27 Archivo Histórico Nacional (AHN), Nobleza, Frías, C. 1252, documento (d). 9-10. Enrique II otorga carta de legitimidad a favor de Fernando, Pedro y Mencía, hijos legítimos de García Álvarez de Toledo, concediéndoles derecho a suceder en los bienes de su padre. 8-VI-1369.
} 
El maestre García Álvarez muere el año 1370 en el cerco de Ciudad-Rodrigo y "su voluntad, de la que deja encargado a su hermano Gutierre, obispo de Palencia y canciller del Reino de Castilla, y aprueba - como otra merced más a su súbdito- el rey Enrique II mediante privilegio librado en Medina del Campo el 21 de marzo de 1370, es repartir su herencia entre su hermano Fernando Álvarez de Toledo, que recibe las villas de Piedrahita, el Barco, el Mirón y la Horcajada, es decir el señorío de Valdecorneja, y "sus hijos". A estos últimos les deja las villas de Oropesa, Jarandilla, Tornavacas y Cavañas. Los tres primeros territorios y en consecuencia el señorío de Oropesa a Fernando Álvarez de Toledo, II señor de Oropesa, y el último territorio y otros bienes semovientes a Mencía. Pedro - por razones no indicadas por Jimeno- se quedará sin heredar ${ }^{28}$.

El tronco genealógico que tiene por primer pariente mayor a Esteban Illán lo continua Fernando Álvarez de Toledo, II señor de Valdecorneja, aunque tal hecho no fue aceptado por la línea de los señores de Oropesa, que desde la condición de hijos legitimados y en consecuencia continuadores por razones de primogenitura del linaje Álvarez de Toledo, litigan con el fin de recuperar toda la herencia dejada por el maestre. Sin embargo Fernando, II señor de Valdecorneja, consolida su casa y disfruta de su herencia, en lo que tiene bastante que ver la toma de partido a favor de Enrique II, que premia el apoyo a su bando concediéndole el cargo de mayordomo de la reina Juana Manuel, así como autorización para que en la principal villa del señorío (Piedrahita) pudiese levantar una casa fuerte. Matrimonia con una pariente lejana (fue preciso dispensa de cuarto grado de consanguinidad), Leonor Fernández de Ayala, hija del IX señor de Ayala. Tienen cinco hijos, de los cuales dos son los más destacados: García y Gutierre. Por disposición notarial, Fernando funda a favor de su hijo primogénito el primer vínculo de la futura casa de Alba: el vínculo formado por las cuatro villas del señorío de Valdecorneja, que es ratificado y por tanto aprobado normativamente mediante privilegio rodado otorgado por Juan I el 10 de marzo de $1385^{29}$.

Una vez consolidada la línea de los Álvarez de Toledo, señores de Valdecorneja, la continuará García Álvarez de Toledo, III señor. A penas destaca por su actividad pública. Todo lo contrario que su hermano Gutierre, oidor de la Audiencia del Rey Juan II, miembro del Consejo Real, y finalmente canciller mayor, a lo que une los importantes cargos eclesiásticos de obispo de Palencia desde 1423, sede episcopal que dejará el año 1439 cuando el papa Eugenio IV lo provea como Arzobispo de Sevilla. Finalmente, el año 1442, contando con el apoyo de su sobrino Fernando Álvarez de Toledo, IV señor de Valdecorneja y I conde de Alba, tras vacar el arzobispado de Toledo por fallecimiento de Juan de Cerezuela, se convierte en arzobispo de la primera iglesia de Castilla. A todo ello, hay que unir algo que será capital para el futuro del linaje y que vuelve a poner de manifiesto en el caso de las familias notorias, como -más allá de los méritos y esfuerzos que desarrolle el pariente mayor- diversos parientes, especialmente si son eclesiásticos o bien no tienen descendencia, pueden colaborar para el engrandecimiento

\footnotetext{
ADA, C. 128, fs. $8-10$.
}

29 ADA, C. 128, fs. 13-14. 
de la $\operatorname{casa}^{30}$. Gutierre Álvarez de Toledo cuya activa y ambiciosa vida política ha sido minuciosamente examinada por Nieto Soria, desarrolla con Enrique III y con Juan II una larga trayectoria pública repleta tanto de ascensos como caídas ${ }^{31}$. En uno de esos ascensos, Juan II el 7 de diciembre de 1429 le hará "merced perpetua e irrevocable de la villa de Alba de Tormes con su tierra, términos, y jurisdicción civil y criminal". Así pues, Gutierre será el primer señor de Alba de Tormes ${ }^{32}$, y cuando fallezca el año 1446, en su testamento otorgado en Torrejón de Velasco el 22 de febrero, deja como único y universal herederos de sus bienes -entre los que se encontraban los señoríos de Alba de Tormes y Alharaz- a su sobrino Fernando Álvarez de Toledo, por entonces I conde de $\mathrm{Alba}^{33}$. Sin lugar a dudas, los especiales lazos que tiene con su tío paterno (no el materno como suele ser más frecuente ${ }^{34}$ ) aportaban un capital imprescindible y de gran valor simbólico para el ascenso del escindido linaje de los Álvarez de Toledo, que el cuarto señor de Valdecornejas y I conde de Alba llevará a uno de sus momentos cenitales. Como acabamos de indicar, si la séptima generación del árbol de los Álvarez de Toledocasa de Alba tienen a su miembro más distinguido en un pariente que trabaja y colabora para el auge de la casa y no en el pariente mayor, la octava generación, va a encontrar a su máximo referente en el patrón y primogénito de la familia: Fernando Álvarez de Toledo, IV señor de Valdecorneja y primer título aristocrático que encontramos en el árbol. De la siguiente manera nos presenta Jimeno tan sobresaliente hecho, aunque no exento de dudas y falta de pruebas contundentes:

"En el intermedio de los años de 1438 hasta el de 1440, obtuvo dicho Sr. Dn Fernando el título de Conde de Alba, porque desde este último en adelante (aunque su título no aparece) ya le intitula el Rey en todas las mercedes, despachos, y cartas, Conde de Alba" ${ }^{35}$.

La herencia de su pariente don Gutierre es importante, pero la consecución del título aristocrático y la ampliación de sus estados señoriales (Salvatierra de Tormes, Granadilla, Miranda, Garganta la Olla, Babilafuente, Villoria...) están cimentadas en el "Real Servicio" a Juan II (desde la milicia como frontero hasta los importante cargos cortesanos de copero mayor o camarero mayor del príncipe Enrique) y en las adecuadas

\footnotetext{
30 Beceiro Pita y Córdoba de la Llave, Parentesco, poder y mentalidad. La nobleza castellana: siglos XII-XV, pp. 83-88, y 251-299.

31 Nieto SoRia, Un crimen en la corte: caida y ascenso de Gutierre Álvarez de Toledo, señor de Alba (1376-1446).

32 Véase para el señorío de Alba de Tormes la obra de Monsalvo AnTón, El sistema político concejil. El ejemplo del Señorío Medieval de Alba de Tormes y su Concejo de Villa y Tierra; y CALDERón OrTega, El ducado de Alba..., pp. 164-165.

33 ADA, C. 128, fs.18-20.

34 Goody, La evolución de la familia y del matrimonio en Europa, pp. 356-358; RuIz DomenEC, "Sistema de parentesco y teoría de la alianza en la sociedad catalana", pp. 132-134; y DeliLLe, El alcalde y el cura..., pp. 255-256.

35 ADA, C. 128, f. 25.
} 
relaciones con su valido Álvaro de Luna mediante alianzas y confederación de defensa mutua. Tan importantes son estos lazos políticos entre el rey y Fernando, que toda la fortuna y auge de la casa se trastoca cuando en 1448, con motivo del llamando "golpe de Záfraga", dado por el condestable Álvaro de Luna, con el visto bueno del príncipe Enrique y de Juan Pacheco ${ }^{36}$, el I conde de Alba cae en desgracia ante el rey y en esa situación permanece hasta la muerte del monarca el año $1454^{37}$. Gracia real recuperada lentamente por la casa tras el acceso al trono de Enrique IV, aunque ahora más que Fernando - que nunca olvidó la responsabilidad de monarca en decidir su prisión-, son su esposa Mencía Carrillo (veneros de plomo que se hallaban en su villa de Salvatierra, y muerto su esposo, tercias de Salvatierra y merced perpetua de los lugares de Abad don Vela, Armenteros...) y su hijo García lo que se ganan la confianza regia ${ }^{38}$.

El árbol de los Álvarez de Toledo, si nos fijamos en el momento en que Fernando se convierte en IV señor de Valdecorneja, nos muestra que aún es un linaje muy distante de los privilegios y poder que tenía la vieja aristocracia castellana. Tanto, que todavía en el plano de las alianzas matrimoniales, siguen moviéndose en el círculo del patriciado toledano, aunque el padre de su esposa va a establecer importantes relaciones con la corte. De hecho, Fernando que se casa antes de obtener el título condal, lo hace con Mencía Carrillo, hija de Pedro Carrillo, señor de Bolaños, alguacil mayor de Toledo, y también aposentador mayor y copero mayor del Rey Juan $\mathrm{II}^{39}$. El suegro, lo que pone de relieve la importancia que tiene el parentesco de afinidad, obtiene del monarca importantes ventajas para su yerno. No se circunscriben exclusivamente a Toledo. En la citada ciudad le consigue, de forma vitalicia, tanto el alguacilazgo (1439) como la escribanía de entregas; en otras partes del territorio castellano: el oficio de merino mayor de Burgos, la alcaidía de sacas y cosas vedadas del obispado de Cuenca, y las tercias de Griñón y Vallecas; a lo que debe añadirse el importante cargo cortesano de copero mayor ${ }^{40}$. Estamos, pues, ante el peso de las relaciones familiares suegro-yerno en el mundo político, o lo que es lo mismo la "yernocracia" o favoritismo de algunos gobernantes por el esposo de su hija para optar a cargos públicos, cuando no existen hijos varones. En consecuencia, ante otra evidencia más, de la funcionalidad política del parentesco entre los linajes urbanos (aparte, claro está de la aristocracia) en la baja edad media castellana ${ }^{41}$.

\footnotetext{
36 SuÁrez Fernández, Enrique IV de Castilla. La difamación como arma política, pp. 75-79; y Franco SiLva, "Las intrigas políticas de Juan Pacheco. Del combate de Olmedo a la muerte de Juan II (1445-1454)", pp. 597-616.

37 Calderón Ortega, "Los riesgos de la política en el siglo XV: la prisión del Conde de Alba (1448-1454)", pp. 41-62; y El ducado de Alba..., pp. 71-85.

38 ADA, C. 128, fs. 34-38.

39 Salazar y Castro, Índice de las glorias de la Casa Farnese, pp. 588-589.

40 ADA, C. 128, fs. 31-32.

41 Monsalvo Antón, "Parentesco y sistema concejil: observaciones sobre la funcionalidad política de los linajes urbanos en Castilla y León (siglos XIII-XV)", pp. 937-969; PÉrez, "En torno a las estructuras de parentesco de la aristocracia castellanoleonesa. Revisión de los modelos interpretativos dominantes", pp. 153-174, y "Estructuras de parentesco y poder aristocrático: la aristocracia leonesa en la alta edad media", pp. 213-231; y Dacosta Martínez, "Poderoso en parientes e rentas: conceptos, discursos y prácticas sobre el linaje en Lope García de Salazar”, pp. 59-87.
} 
Será la última ocasión en la que la alianza matrimonial de los descendientes de la "aristocracia ciudadana" de Toledo, como los califica hasta ese momento Salvador de Moxó $^{42}$, se restrinja al círculo de los caballeros toledanos. Los Álvarez de Toledo que tiene como pariente mayor a Fernando, cimentados no solo en ser destacados miembros de la "nobleza nueva" trastamarista, sino en sus riquezas, amplitud de estados señoriales y disfrute de título aristocrático y mayorazgo (ampliado por Fernando el año 1447 al incorporar a Valdecorneja -entre otros- los dominios señoriales de Alba de Tormes), en la siguiente generaciones dan mayor lustre al árbol familiar. A partir de la segunda mitad del siglo XV junto al servicio al rey y los réditos que genera, va a resultar importantísimo las alianzas matrimoniales con la vieja aristocracia de sangre castellana, con sangre real, como los Enríquez. El parentesco de alianza va a ser de notable importancia.

\section{Afianzamiento sociopolítico de la casa de Alba: relaciones matrimoniales consan- guíneas y finalmente homogámicas con los Enríquez y los Benavente (1447-1531)}

Comenzábamos el artículo recogiendo la propuesta de G. Delille relativa a que consanguinidad y matrimonio ocupan un lugar central en la constitución de relaciones sociales y políticas en los últimos siglos de la edad media y durante los siglos modernos. Y precisamente Alba en los inicios de su condición de casa nobiliaria va hacer uso del matrimonio y la consanguinidad con esos propósitos.

Situemos el ambiente político y social del año 1447. Nuevamente se vuelve a hacer realidad lo expuesto por halconero mayor del rey Juan II, Pedro Carillo, pertinente a que las bandas nobiliarias continuamente promovían "bollicios e ligas e monipodios" ${ }^{3}$. En esas ligas como ya se ha indicado, toma parte el I conde de Alba. En concreto Fernando Álvarez de Toledo se integra en el partido del rey de Navarra, y entra en estrecha relación con su cabeza visible en Castilla: Fadrique Enríquez, II Almirante de Castilla y II señor de Medina de Rioseco, suegro del rey de Navarra, y la tercera persona con más rentas en el Reino de Castilla -solo superado por el príncipe Enrique y el condestable Luna-. Casi a la par que la relación política, también tiene lugar una alianza matrimonial - poniendo de manifiesto lo indicado por Isabel Beceiro y Ricardo Córdoba de la Llave de confederaciones político-matrimoniales ${ }^{44}$, , pues el hijo primogénito del I conde de Alba, García, va a casar con María Enríquez, hija de Fadrique y de su segunda esposa, Teresa de Quiñones. El pacto político a corto plazo no rinde frutos satisfactorios, ya que obliga a los Alba a abandonar sus buenas relaciones con el Condestable Álvaro de Luna, a enfrentarse al príncipe Enrique, y a tener en su contra a una parte de la alta nobleza castellana. Precisamente esos nobles, encabezados por Luna y el marqués de Villena dan el "golpe de Zafraga", con el fin de hacerse con mayor poder y eliminar del espacio político -entre otros- a Fadrique Enríquez y a Fernando Álvarez de Toledo.

\footnotetext{
42 Moxó, "El auge de la nobleza urbana...”, p. 486.

43 Carrillo de Huete, Crónica del Halconero de Juan II, p. 11.

44 Beceiro Pita y Córdoba de la Llave, Parentesco, poder..., pp. 312-318.
} 
Sin embargo en el terreno de las relaciones familiares si aporta réditos positivos. Da inicio una etapa de aproximación al importante linaje de los Enríquez, de estirpe real, que acabaría sirviendo para consolidar en el escalafón aristocrático a la casa de Alba, una vez superada la crisis que vive tras su pacto político ${ }^{45}$.

La alianza matrimonial - como ha indicado D. Sabean y S. Teuscher- va a ser de enorme importancia para los grupos sociales con más privilegios que pretenden consolidar relaciones políticas. El matrimonio -y esto es plenamente trasladable al reino de Castilla en el siglo $\mathrm{XV}^{46}$ - configura relaciones duraderas y proporciona elementos favorables a largo plazo para unir a casas y familias, más cuando estas tienen aspiraciones de poder. Aunque advierten los autores citados, no podemos pensar que las relaciones matrimoniales supongan unas relaciones entre las partes contrayentes plenamente igualitarias ${ }^{47}$. Por origen y distinción del linaje, rentas y poder no hay ninguna duda que en el momento de la primera alianza, los Enríquez era el linaje patrón. Aunque también es cierto, que conforme transcurre el siglo XV y, sobre todo en el siguiente, los servicios a la Monarquía y los éxitos políticos acabaran equilibrando aquellas relaciones y posiblemente poniendo por delante a los Alba. Jimeno nos indica cómo se produce esa alianza por parte de las dos casas. Es cierto que el archivero desconoce las relaciones políticas que dimanan del golpe de Záfraga, sin embargo no se puede decir lo mismo respecto a las de parentesco. Antes de la unión de las dos casas a través del matrimonio el año 1448 de García Álvarez de Toledo, futuro II conde de Alba, y María Enríquez (véase figura 1), ya habían existido relaciones de parentesco, como lo probaba el que fuesen necesarias dispensas matrimoniales al concurrir consanguinidad de tercer grado. Los contrayentes tenían como bisabuelos comunes a Fernando Álvarez de Toledo, $2^{\circ}$ señor de Valdecorneja, y a Leonor de Ayala. Aunque la consanguinidad no la origina directamente el tronco de los Álvarez de Toledo, sino una rama colateral, ocupada por María de Toledo, hija de los citados Fernando y Leonor, casada con Diego Hernández o Fernández de Quiñones, merino mayor de Asturias, señor de Luna, e igualmente declarado trastamarista y bien relacionado con los Enríquez ${ }^{48}$. Su hija Teresa casará en segundas nupcias con Fadrique Enríquez, II Almirante, entre cuyos descendientes se encuentra María Enríquez, consorte del II conde de Alba.

Jimeno considera el matrimonio de García Álvarez de Toledo y María Enríquez como ventajoso, pues es la primera vez que la casa toledana entronca con otra de estirpe real: "Dicha Sra Da María Henriquez fue hermana carnal de la Señora Reyna Da Juana Henriquez muger segunda que fue del Sor Rey Dn Juan el $2^{\circ}$ de Navarra y Aragón, padres del Sor Rey Catholico Don Fernando"49

\footnotetext{
45 Calderón Ortega, El ducado de Alba.... pp. 72-73; y SuÁrez Fernández, "Introducción a un linaje", pp. 9-19.

46 Beceiro Pita, "Parentesco y alianzas políticas en Castilla (siglo XV"), pp. 9-28.

47 Sabean and Teuscher, "Kinship in Europe: A New Approach to Long-Term Development", pp. 1-26.

48 Álvarez Álvarez, “Los Quiñones-Condes de Luna durante la Baja Edad Media”, pp. 45-60. Igualmente se encuentran interesantes referencias sobre el linaje Quiñones en el libro de Torres, Palat de Rey: el Palacio de los Quiñones, Condes de Luna y su entorno urbano palatino, pp. 102-110.

49 ADA, C. 128 , f. 43.
} 
FigURA ${ }^{0} 1$.

Relaciones de consanguinidad de tercer grado entre García Álvarez de Toledo, II conde de Alba y I duque de Alba y María Enríquez.

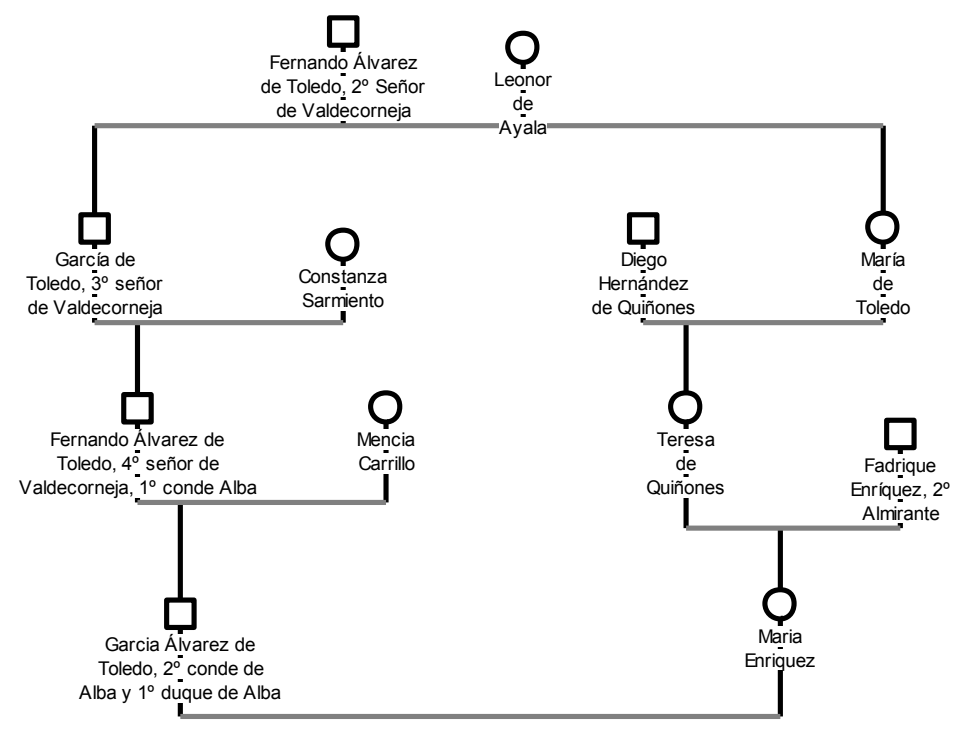

Sin embargo lo llamativo -solo entendible por la caída en desgracia de los Enríquez durante el reinado de Felipe $\mathrm{V}$ y el perjuicio que podía ocasionar a mitad del siglo XVIII su deslealtad con la dinastía borbónica ${ }^{50}$ es que Jimeno obvie el origen real de naturaleza castellana que tienen los propios Enríquez (véase figura 2). Tanto la reina Juana Enríquez -en realidad solo hermana de padre, pues su madre fue la primera esposa de Fadrique Enríquez, Marina Fernández de Córdoba- como María Enríquez eran descendientes del fundador del linaje Enríquez: el infante Fadrique de Castilla, hijo natural del rey Alfonso XI de Castilla y de Leonor de Guzmán, y nietas del primer almirante, Alonso Enríquez, al que se tiene por primer pariente mayor de la casa. Por tanto, el II conde de Alba es cierto que estaba casado con una esposa perteneciente a una linaje real, pero María lo era, ante todo, por descender directamente de los Enríquez. A lo que debe sumarse su enorme capital relacional, consecuencia también del parentesco, con otras familias de la vieja aristocracia como Pimentel, Mendoza, Ayala, Velasco, Manrique, Osorio... ${ }^{51}$.

Lo que desconoce el archivero, no debió desconocerlo la casa de Alba, pues la memoria de antepasados tan importantes entre la vieja nobleza castellana daba gran consistencia a una familia de la nueva nobleza, que de nuevo por su servicio a los Trastámaras -en

50 González Mezquita, Oposición y Disidencia en la Guerra de Sucesión Española. El Almirante de Castilla; León SAnZ, El Archiduque Carlos y los austracistas: Guerra de Sucesión y exilio; y AGÜERO CARnero, "El ocaso de los Enríquez de Cabrera. La confiscación de sus propiedades y la supresión del almirantazgo de Castilla", pp. 132-153.

51 Ortega Gato, "Los Enríquez, Almirantes de Castilla”, pp. 23-46. 
una etapa de enorme conflictividad política y lucha de bandos, como es la que se registra en el reino de Castilla desde $1464^{52}$ - va a subir un escalón más dentro del grupo nobiliario. Fue, sin duda, importante el matrimonio del futuro II Conde de Alba con María Enríquez. Pero desde la muerte de su padre el año 1464, y aún antes, Jimeno no deja de aportar pruebas que muestran la recuperación de la casa condal de Alba. Inicialmente, en ello tuvo bastante que ver -olvidando las viejas desavenencias existentes de cuando Enrique fue príncipe- la aproximación al rey Enrique IV. García aprovecha la política de "bondad y clemencia" 53 del monarca para recuperar las villas pérdidas después de Zafraga, y, a continuación, para ampliar sus estados, como hicieron otras tantas casas aristocráticas (Mendoza, Girón, Pimentel, Luna, Manrique...) que ponen sus intereses por delante de los del Reino ${ }^{54}$. Buena prueba de la relación entre el rey y el conde, es la carta del primero el 3 de febrero de 1465, considerándolo "leal servidor y amigo" "55; y, especialmente, que Enrique IV y su esposa Juana lo sitúen en el primer círculo de los nobles afectos:

"Estando en Madrid el 6 de junio de 1464 juraron en todo forma de guardar la persona, honra, casa, estado y bienes del Sor Conde Dn García y que de él harían tanta quenta como de los más principales Cavalleros de estos Reynos" ${ }^{56}$.

Las mercedes no dejaron de llegarle. Enrique IV tras restituirle a comienzos de 1465 el lugar de Villanueva de Cañedo, le otorga gracias de mucha mayor envergadura que incrementan sus estados señoriales: la ciudad y fortaleza de Coria, la fortaleza de Bernardo del Carpio en tierras de Salamanca, Ciudad Rodrigo, Plasencia (confiscada previamente a Álvaro de Zúñiga) y ya el año 1466, la villa y fortaleza de Carrión ${ }^{57}$.

Al año siguiente, conforme al relato de Jimeno, quien le otorga gracias y mercedes es el príncipe Alfonso. Se convierte en realidad lo que decía la coplilla que recoge el cronista Diego Enríquez Fernández, de que García se "vende a cada cantón". El carácter de García, en el que prevalece la falta de escrúpulos, y los incumplimientos de Enrique IV a la hora de hacer entrega efectiva de las gracias o bien incumplimientos económicos para mantener las tropas con la que colaboraba con el bando real, motivan que a principios del verano de 1467 milite secretamente en el bando del príncipe Alfonso $^{58}$. Las mercedes otorgadas por el príncipe continúan engrandeciendo la casa

\footnotetext{
52 Junto a la citada obra de SuÁREz FERnÁndez, Enrique IV de Castilla..., resultan imprescindibles para abordar el tema de los bandos los trabajos de VAL VALDIVIESO, "Los bandos nobiliarios durante el reinado de Enrique IV”, pp. 249-294, y DíAz DE Durana, "Las luchas de bandos: ligas nobiliarias y enfrentamientos banderizos en el nordeste de la corona de Castilla”, pp. 81-112.

53 SuÁrez Fernández, Enrique IV de Castilla..., pp. 130-132.

54 Calderón Ortega, El ducado de Alba..., pp. 90-97; y SuÁrez Fernández, Enrique IV de Castilla..., pp. 287-387.

5 ADA, C. 128 , fs. 44-45.

ADA, C. 128, f. 44.

ADA, C. 128, fs. 45-48.

58 Calderón Ortega, El ducado de Alba..., pp. 90-93.
} 
FIGURA $\mathrm{N}^{\mathrm{o}} 2$.

Inicio de la genealogía de los Enríquez. Tomada del árbol genealógico de la casa de Alba de Liste (Archivo Histórico Nacional, Nobleza, Baena, caja 259, documento 122).

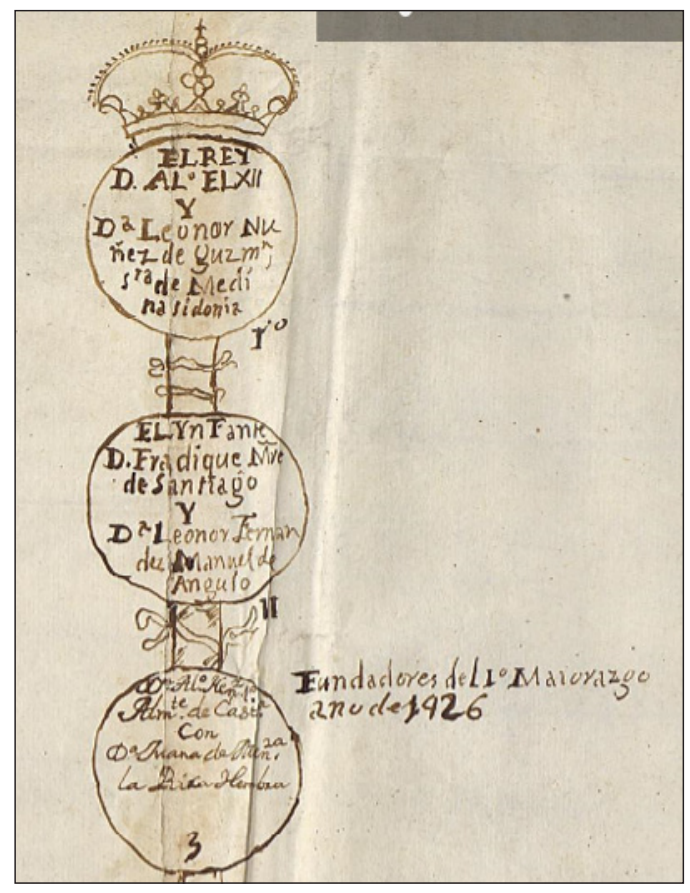

y el señorío del II conde de Alba: confirmación de la merced realizada por Juan II de los oficios de alcalde mayor de sacas y cosas vedadas de la ciudad de Cuenca y juez de pagas del arzobispado de Sevilla y del obispado de Cádiz; o bien la transformación en perpetuas - hasta ese momento, 1468, solo eran por vida del conde- de alcabalas y tercias provenientes de sus señoríos ${ }^{59}$.

La muerte de Alfonso en junio de 1468, precisamente obliga a García a desandar el camino y reconstruir sus relaciones con Enrique IV, que ahora se encontraba atrapado por otro grave problema: su propia sucesión. La misma parecía resuelta tras la ceremonia de Valdelozoya en octubre de 1470. Su hija Juana sería la heredera. En ese ambiente, ciertamente nada consolidado, pues su hermana Isabel y su esposo Fernando no renunciaban a sus derechos sucesorios y de nuevo flotaba ambiente de guerra civil ${ }^{60}$, primeramente, según señala Jimeno, el rey le otorga al II conde de Alba una escritura de concordia el 20 de abril de 1471, prometiéndose mutuamente "amistad y alianza". También mercedes para suplir aquellos compromisos anteriores sobre donaciones señoriales - caso concreto de Ciudad Rodrigo- que no había cum-

59 ADA, C. 128 , fs.48-49.

60 SuÁrez Fernández, Enrique IV de Castilla..., pp. 453-477. 
plido, como 1500 vasallos de la ciudad de Ávila y su correspondiente jurisdicción civil y criminal, así como rentas. A lo que también sumaba, entre otras mercedes, concesión perpetua de las alcabalas y tercias cobradas en sus señoríos, otros 300 vasallos en Galicia, o bien la concesión de una de las contadurías mayores de Castilla, que el conde entregaría a alguno de sus hijos. Pero todo ello, iba acompañado de una obligación: "con tal que sirviese y siguiese -apunta finamente Jimeno- a su Magd y la princesa $\mathrm{D}^{\mathrm{a}}$ Juana su hija"61.

En la segunda mitad del año 1471 llegaron más mercedes, relativas a juros de heredad situados sobre las alcabalas y tercias de sus estados, y sobre Medina del Campo y sus tierras $^{62}$. Pero la más relevante, tanto desde el punto de vista social como político la obtiene el año 1472, en que le otorga el título de duque:

"El mismo Monarcha dn Henriqe $4^{\circ}$ en el año 1472 dio titulo original a dicho Sor Conde dn Garcia para que desde allí en adelante se pudiera intitular Duque de la ciud. o villa que poseyese y lo mismo su primogto y demás subcesores"63

Jimeno no indica exactamente qué día y mes recibe tan importante merced. Pero en la documentación que maneja, desde el 2 de febrero de 1472 menciona a García Álvarez de Toledo como duque. Va a resultar un año nuclear para la plena consolidación de la casa de Alba dentro del estamento nobiliario, pues a finales del mismo, en concreto el 20 de diciembre, Enrique IV concedía al "Sr. Duque Don García" y a sus descendientes el título de marqués de Coria ${ }^{64}$.

Así pues, concluye el reinado de Enrique IV, fallecido el 12 de diciembre de 1474, en condiciones "tristes" y sin haber resuelto el problema sucesorio ${ }^{65}$. En cambio la casa de Alba forma parte ya del círculo de la primera nobleza del reino de Castilla. Las relaciones matrimoniales establecidas con otras familias, al menos en el caso de las hijas del I duque, iniciadas poco después de obtener el título, permiten apreciar que sus matrimonios están en otro escalón social. Hemos visto que el I conde pudo casar a su primogénito con una descendiente del rey Alfonso XI, pero los otros matrimonios convenidos eran con parientes con menos distinción social, como sucede con el matrimonio de su hija Mayor Carrillo de Toledo con el I conde de Oropesa, Fernán Álvarez de Toledo, y el de las otras hijas con señores jurisdiccionales. El II conde de Alba y I duque de Alba se aprecia con toda claridad, logra que los matrimonios de sus hijas sean con grandes, que a su vez tienen un relevante papel político al final del periodo bajomedieval, como sucede con los establecidos con las casas -situadas por Quintanilla

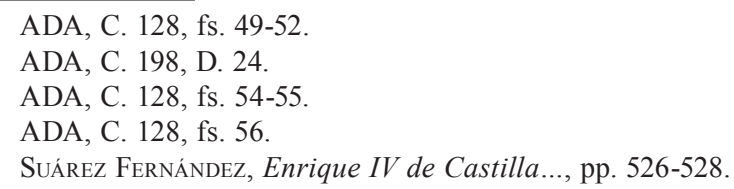


Raso dentro de la "cúspide nobiliaria"66 - de Alburquerque ${ }^{67}$, Osorno y Feria. Sin lugar a dudas, los matrimonios que denotan la alta condición social y la influencia política de la casa de Alba, son, especialmente, los entablados por partida doble con la casa de Alburquerque. Mencía de Toledo casa en el verano de 1476 con Beltrán de la Cueva -viudo de Mencía de Mendoza-, y su hermana Francisca se acuerda que lo hará más adelante con el hijo del duque, es decir con Francisco de la Cueva, conde de Ledesma ${ }^{68}$. ¿Además de la homogamia social pudieron existir razones políticas? Nuestras fuentes no nos permiten demostrarlo. Pero es conocido que los Alba -junto a los Mendoza, Benavente, Salinas, Paredes, Manrique, Almirante y con posterioridad Feria- se alinea junto a la casa de Alburquerque durante el tiempo que Beltrán de la Cueva es favorito de Enrique IV $^{69}$, y que la alianza política ${ }^{70}$ se refuerza estrechamente tras la unión de las casas a través de la estrategia de los matrimonios dobles.

García Álvarez de Toledo en el caso de sus hijos varones, empezando por el primogénito Fadrique -al que le corresponde preservar la casa a través de la institución del mayorazgo $^{71}$-, también desarrolla alianzas matrimoniales cuyo objetivo es que las esposas estén próximas en estado social y que las casas a las que pertenezcan tengan destacada relevancia política. Pero a diferencia de las hijas, no se establecen acuerdos con casas con las que previamente hay amistad; por el contrario, se busca precisamente a través del matrimonio, mejorar relaciones con casas con las que no ha existido coincidencia de bando. En consecuencia, García no sigue la misma estrategia que su padre, cuando

${ }_{66}$ Quintanilla Raso, "El engrandecimiento nobiliario...”, pp. 63-66.

67 Franco Silva, Estudios sobre Don Beltrán de la Cueva y el ducado de Alburquerque; Carceller CerVIÑo, "Nobleza cortesana, caballería y cultura: la casa ducal de Alburquerque", pp. 215-263; y QuinTANILLA Raso y Carceller Cerviño, "La construcción de la memoria de las grandes casas nobles en la Corona de Castilla. El marquesado de Priego y el ducado de Alburquerque", pp. 271-302.

68 Fernández de Béthencourt (Historia genealógica y heráldica de la monarquía española, Casa Real y Grandes de España, p. 233), nos muestra como en las capitulaciones entre Mencía y Beltrán, fechadas el 13 de junio de 1476, se acuerda igualmente el matrimonio de los hijos de Beltrán de la Cueva y García Alvarez de Toledo: "y se convino, además, desde entonces que cuando tuviesen edad se casasen Don Francisco Fernando de la Cueva, primogénito del Duque, con Doña Francisca de Toledo, hermana de la nueva Duquesa, y de morir antes él, que esta Señora casase con Don Antonio de la Cueva, que era el hijo segundo, y de morir antes ella, que el Don Francisco se enlazara con Doña María de Toledo, la hija tercera del Duque de Alba, que fué después Condesa de Feria".

69 Carceller Cerviño, "Los bandos nobiliarios y la carrera política: ascenso y privanza de Beltrán de la Cueva", pp. 783-801.

70 Desde un punto de vista antropológico, el análisis de los matrimonios con fines políticos tiene un adecuado análisis en François Heritier, L'exercice de la parenté.

71 ADA, C. 128, f. 69. Jimeno recoge la fundación por parte de García Álvarez de Toledo de cinco mayorazgos a favor de cinco hijos varones: Fadrique, Gutierre, Pedro, Enrique y García. Realiza tal formalización mediantes escrituras públicas llevadas a cabo en Alba de Tormes el 16 de octubre de 1487 ante Pedro Alonso de Salvatierra. Decisión refrendada en el codicilo otorgado nuevamente en Alba de Tormes por el I duque ante Rui Fernández el 26 de mayo de 1488. Y de esos cincos mayorazgos, el principal era el inicial mayorazgo de Valdecorneja, al que García decide agregar de forma definitiva las villas de Alba de Tormes y Granadilla, y la ciudad de Coria. No era un mayorazgo de "rigurosa agnación", pero sus cláusulas si determinaban que lo heredase el hijo mayor legítimo, y después sus nietos y demás sucesores, y que si en algún momento recaía en "hembra, que su marido tragese Armas y Apellidos, y en su defecto que pasaré al inmediato subcesor". 


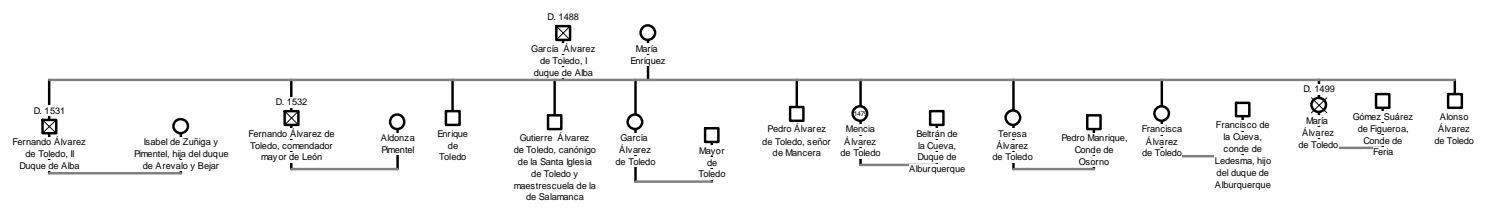

Genealogía 2. Descendientes de García Álvarez de Toledo, I duque de Alba, y María Enríquez, y matrimonios acordados por sus hijos. Véase página 59. 
lo había casado a él con una hija de los Almirantes, debido a sus prietas relaciones políticas. Aunque en estas decisiones sobre el matrimonio del primogénito también va a influir decisivamente la corona y en concreto la política seguida por los Reyes Católicos para recomponer su relación con las casas nobiliarias que habían apostado por la opción de Juana como legítima reina de Castilla. El matrimonio de Fadrique, futuro II duque de Alba, va a ser con Isabel de Zúñiga Pimentel, hija de Álvaro de Stuñiga, duque de Arévalo y de Béjar. Álvaro había estado mucho más próximo a los Pacheco que a los Cueva $^{72}$, cuando don Beltrán se convierte en la persona de confianza de Enrique IV y desplaza de tan privilegiada situación a Juan Pacheco; y también fue, como expone Zurita, "el más apasionado por ver al rey de Portugal rey de Castilla"’3. Por todo ello, cuando en Béjar (probablemente el año 147974) enlazan Fadrique Álvarez de Toledo e Isabel de Zúñiga y Pimentel, la casa de Alba está reorientando y expandiendo sus relaciones políticas, pero sobre todo, está sirviendo a la monarquía castellana y siguiendo las pautas que esta desarrolla para imponer su dominio sobre las casas nobiliarias rebeldes y obligar a que tengan relaciones de "amigos" casas habitualmente confrontadas.

Que las relaciones políticas no fuesen buenas entre Álvarez de Toledo y Stuñigas, no impedía que hubiese anteriores relaciones familiares, que en alguna manera también debieron servir para restablecer relaciones en ambos sentidos. Fadrique e Isabel tenían en común tatarabuelos: Fernando Álvarez de Toledo, segundo señor de Valdecorneja, y Leonor Ayala; consiguientemente, para su boda fue preciso una dispensa de consanguinidad de cuarto grado. Aunque al igual que ocurre con el parentesco de sangre del padre de Fadrique, el duque García, verdaderamente hay que remontarse al matrimonio de María de Toledo -lo que sin lugar demuestra la importancia de lo femenino, o la no "desvalorización de lo femenino", como señala Francois Heretier ${ }^{75}$ - y Diego Fernández o Hernández de Quiñones para entender los vínculos sociales y políticos que arrojan las relaciones de sangre. Una de las hijas de María y Diego casa con el miembro de una destaca familia aristocrática de origen portugués e importante presencia en la política castellana durante el siglo XV, Alfonso Pimentel ${ }^{76}$, cuya hija Leonor, con bastante probabilidad, por lo que sabemos de alianzas de bandos, enlaza con Álvaro de Zúñiga para reforzar los vínculos entre Pachecos (igualmente linaje de origen portugués), Pimentel y Zúñigas. No obstante el reinado de

\footnotetext{
72 AHN, Nobleza, Osuna, C. 417, D. 7. Escritura de promesa y seguro otorgada por Álvaro de Zúñiga, [II] conde de Plasencia, y Juan Pacheco, marqués de Villena, por la cual se comprometen a entregar la ciudad de Toro (Zamora) a Rodrigo [Alfonso] Pimentel, [I] conde-duque de Benavente, si el infante Alfonso es nombrado rey de Castilla, Benavente, 26-IV-1465.

73 ZuRita, Los cinco libros postreros de la segunda parte de los Anales de la corona de Aragón, pp. 256-257

74 AHN, Nobleza, Osuna, C. 217, D. 31-34. Relaciones de cuentas de la dote y gastos para la boda efectuada entre Isabel de Zúñiga, hija de Álvaro [López] de Zúñiga y Leonor Pimentel [Zúñiga, I] duques de Plasencia, y Fadrique [Álvarez] de Toledo, hijo de los [I] duques de Alba [de Tormes], García Álvarez de Toledo Enríquez y de María Enríquez de Quiñones. 1-10-1479.

75 Héritier, Masculino/Femenino II.

76 Álvarez Palenzuela, "Protagonismo político de un linaje portugués en la Castilla de Juan II: Rodrigo Alfonso Pimentel", pp. 1301-1310; Romero Portilla, "Protagonismo del partido portugués en la política castellana del siglo XV", pp. 187-212. Obra básica para entender la implantación del linaje Pimentel en Castilla: Beceiro Pita, El Condado de Benavente en el siglo XV, 1998.
} 


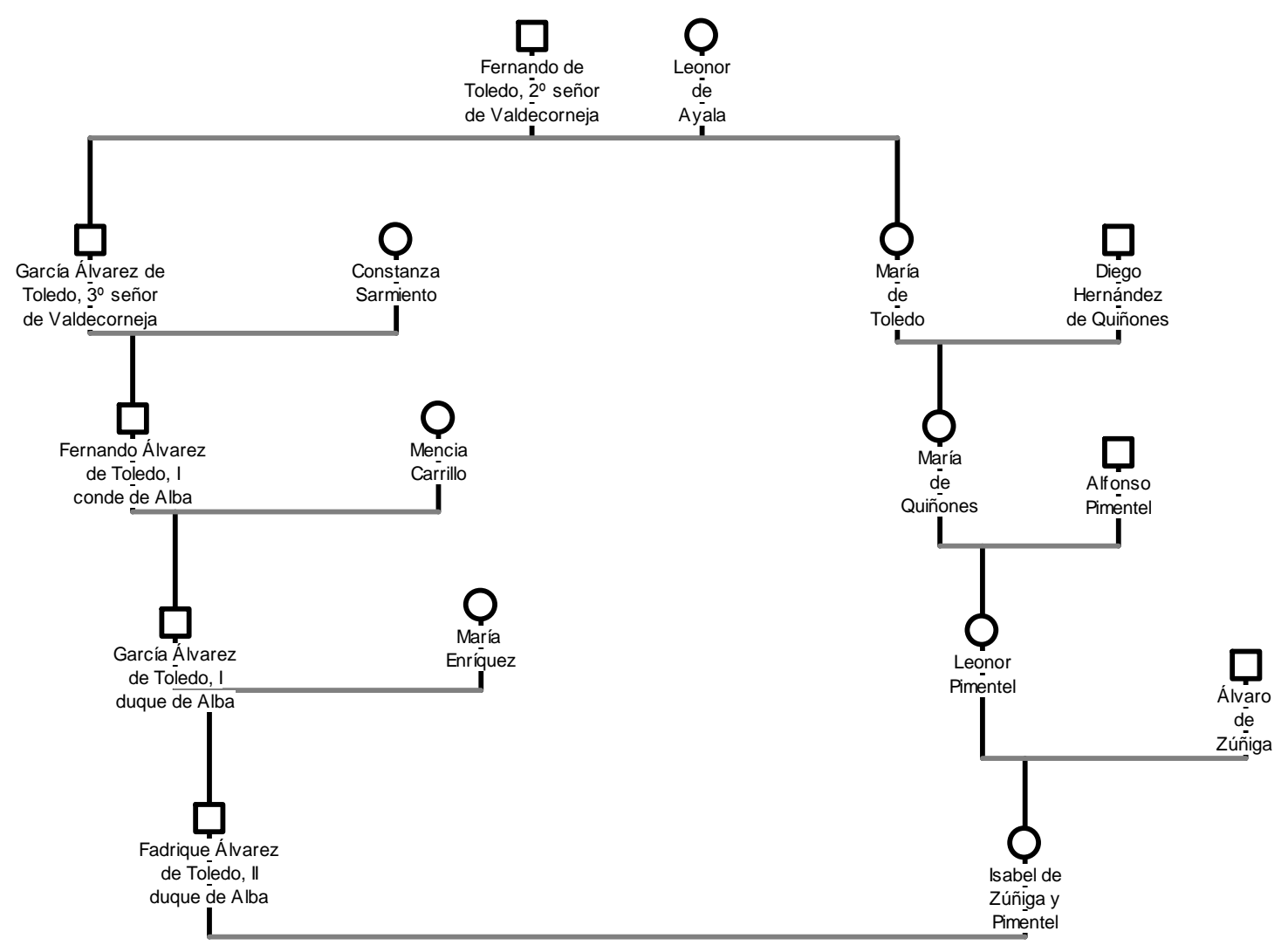

Genealogía 3. Relaciones de consanguinidad de cuarto grado entre Fadrique Álvarez de Toledo, II duque de Alba e Isabel de Zúñiga y Pimentel. Véase página 60. 
Isabel y Fernando abre un nuevo periodo, en el cual los bandos tienen cada vez menos peso, o al menos los monarcas no desean que los tengan; y sí, en cambio, la formación de un destacado grupo aristocrático, que desde la paz territorial sirva a los intereses de la Monarquía castellana. Fadrique e Isabel son prototipos de ese nuevo modelo de matrimonio que acuerda la cúspide nobiliaria, no para bandear entre ellos, sino para servir al monarca y obtener privilegios que aumenten su patrimonio, su influencia política y su distinción social -hasta el punto de convertirse en la élite nobiliaria-.

Las mercedes concedidas por Isabel en unos casos, por Isabel y Fernando como Reyes Católicos en otros, por la Reina Juana y por Fernando en su etapa de regente -nada en cambio durante el reinado de Felipe I, con quien las relaciones fueron tirantes y encontradas, hasta el punto de no visitar la corte ${ }^{77}$ - muestran el favor que le dispensaron al titular de la casa de Alba y la confianza depositada en el II duque. El año 1498, con motivo de ausentarse los Reyes Católicos de Castilla, lo nombran -conjuntamente con el Condestable, Bernardino Fernández de Velasco- gobernador de los reinos de Castilla, León y Granada. En 1503, los Reyes Católicos -indica Jimeno, aunque posiblemente la decisión la tomase Fernando- le encargan la dirección del ejército que está luchando contra Luis XII, al intentar ocupar el condado del Rosellón, perteneciente al Reino de Aragón. Pasado el breve reinado de Felipe I, en la segunda regencia de Fernando, su papel fue bastante destacado. Jimeno informa sobre concesión de mercedes económicas (mineros de metales preciosos, juros de heredad sobre el oro que procedente de América llegase a la Casa de Contratación), pero resalta especialmente su sobresaliente papel en la guerra de Navarra ${ }^{78}$ :

"El año de 1512 le gasto dicho señor Duque dn Fadrique en la conquista del Reyno de Navarra, y en ella se mantubo hasta que en efecto expelió de él a Dn Juan de Labrit (Albret) y Da. Cathalina de Fox (Foix) por schimathicos"79.

Concluida la conquista inicial de Navarra, Fernando le encarga el 20 de septiembre de 1512, en calidad de "plenipotenciario" no solo de "S.M.C", sino de todos los miembros que forman la Santa Liga (Venecia, Papado, Inglaterra e Imperio) que alcance una tregua con Luis XII. Los méritos que en opinión de Fernando había conseguido el duque Fadrique, se van a ver recompensados, mediante privilegio emitido por Juana I (no por el regente), que a través de un privilegio fechado el 16 de febrero de 1514 , amplia los estados señoriales de la casa de Alba. Si hasta entonces se localizan en la vieja Castilla y Extremadura, ahora se amplían hasta el Reino de Granada. Juana hace "merced perpetua" al II duque y a sus sucesores de la villa (con jurisdicción civil y criminal) de Huéscar y del lugar de Castilleja ${ }^{80}$.

7 Calderón Ortega, El ducado de Alba..., p.123-125; y Felipe el Hermoso, 2008.

78 Monteano Sorbet, La Guerra de Navarra (1512-1529). Crónica de la conquista española; y Floristan Imizcoz, (coord.), 1512. Conquista e incorporación de Navarra. Historiografía, Derecho y otros procesos de integración en la Europa renacentista.

79 ADA, C. 128 , f. 81.

80 ADA, C. 128 , f. 82. 
En los años que le quedan de vida a Fernando II, sigue registrándose una importante presencia política del II duque en su equipo de gobierno. Cuando fallece el regente, en enero de 1516, permanece -aunque chocando en diversas cuestiones- en la vida política durante los casi dos años que dura la regencia del Cardenal Cisneros. Sin embargo, en el reinado de Carlos I su papel va en paulatino ocaso ${ }^{81}$. Jimeno no recoge ni un solo hecho político después de 1517, aunque es cierto que fue uno de los pocos nobles castellanos que acompaña a Carlos en su viaje a Alemania para ser coronado emperador y que se reunía con él para "tomar consejo"; o bien, que el año 1526, le da entrada en el Consejo de Estado con motivo de la reorganización de una de las más importantes instituciones del sistema polisinodial ${ }^{82}$. El archivero tampoco, llamativamente -lo que confirma las actuales tesis sobre que no se produce la creación de la grandeza de España el año $1520^{83}$ - recoge la concesión del Toisón de Oro, junto a otros nueve integrantes de la elite aristocrática. En ese plano de la distinción social, únicamente apunta la gracia otorgada el año 1523 que le permitía agregar al primitivo mayorazgo de Alba el señorío de Huéscar, la fortaleza de Bernardo del Carpio, el lugar de Alharaz, el juro sobre el oro que venía de las Indias a la casa de Contratación de Sevilla y otros heredamientos menores. Mayorazgo que heredaría el primogénito, o en su ausencia su inmediato sucesor, y que Fadrique decide incrementar con las últimas agregaciones en bienes materiales obtenidos por la casa para que prosiga creciendo el alto rango de la misma y para que su titular se encuentre entre los poseedores de unos de los mayores vínculos ostentados por la nobleza de la Monarquía Hispánica.

Posiblemente sea cierto que conforme pasaban los años fue perdiendo influencia política, pero también lo es, que desde octubre de 1510 , la sucesión de su casa es un tema de enorme importancia; vital, como veremos más adelante, para impedir que se pierda la troncalidad de la misma. La política entendida como fin para conseguir poder y estar lo más próximo al centro del poder, es relegada como fin primordial por parte de Fadrique, en lo que tiene bastante que ver su idea de casa. La entiende de una forma muy próxima a la propuesta analítica de Otto Brunner. La casa forma una comunidad familiar amplia e indisociable, compuesta tanto por miembros con lazos de sangre como por otros que no los tienen; quienes componen esta comunidad, tienen el deber de aceptar el amplio conjunto de atribuciones que tiene el jefe, es decir que a él solo le corresponde la dirección y administración de las personas y bienes; y que todas esas personas que constituyen parte de la comunidad familiar deben actuar para su conservación y engrandecimiento, obteniendo en contrapartida: protección y beneficios para el desarrollo de sus vidas ${ }^{84}$.

Con tales principios actúa Fadrique para organizar la política matrimonial de su casa. El año 1503 enlaza a su hijo primogénito García con Beatriz Pimentel, hija de los

\footnotetext{
Calderón Ortega, El ducado de Alba..., pp. 132-137.

Martínez Millán, La corte de Carlos V, T. III, pp. 32-33.

3 Soria Mesa, La nobleza en la España Moderna, pp. 55-74.

${ }^{84}$ BRUNNER, Terra e potere: strutture pre-statuali e pre-moderne nella storia costituzionale dell'Austria medievale.
} 
condes de Benavente. Los dos jefes de las casas, desde la Guerra de Granada -conforme relata en los Anales de Aragón Jerónimo de Zurita- andaban confederados. Si la confederación en bastantes casos es antesala de parentesco, en este caso así sucede. Las ligas o por los menos la proximidad política y militar da paso a un acuerdo entre ambas casas, compromiso en el que nuevamente es muy determinante la intervención de los monarcas: "se concertó con la voluntad del Rey y de la Reyna" ${ }^{85}$. En buena medida la participación real se debe, junto al deseo de regular las relaciones entre familias aristocráticas, al hecho, de que -como nos informa Jimeno- García Álvarez de Toledo desde 1499 es "contino" real ${ }^{86}$. No obstante "el concierto" que desde 1501 intentan establecer ambas familias no fue fácil de alcanzar por los diversidad de opiniones que dentro de la casa de Benavente mantienen María Pacheco, viuda desde el año 1499 del IV conde de Benavente, y su hijo y nuevo jefe de la casa, Alonso Pimentel ${ }^{87}$; heredero, aunque no primogénito, pues quién lo era, Luis Pimentel fallece antes que su padre. La boda entre García y Beatriz (poseedora de un vínculo creado a su favor por su madre María Pacheco ${ }^{88}$ ) no tendrá lugar hasta 1503. Abierto el camino del acuerdo entre ambas casas, como se viene indicando por la decisiva participación de los Reyes Católicos, finalmente lo que se consigue es un doble matrimonio ${ }^{89}$ con la casa de Benavente. Además de llegar Beatriz Pimentel a la casa de Alba como futura duquesa, un varón de la casa, Pedro de Toledo ${ }^{90}$, al que en esos momentos no adorna ningún título y que ocupa un lugar segundón dentro del árbol genealógico, pasa a la casa de Benavente, o para ser más exactos a la casa de Villafranca del Bierzo, como consorte de la aún no núbil y futura II marquesa de Villafranca, María Osorio Pimentel, hija del primer primogénito y heredero que había tenido la casa de Benavente, el ya citado Luis Pimentel ${ }^{91}$. Fadrique, II duque de Alba, no llegará a verlo, pero la política matrimonial va a dar resultados muy positivos. Su nieto Fadrique Álvarez

\footnotetext{
85 Zurita, Historia del Rey Don Hernando el Catolico, de las empresas y ligas de Italia, T. 5, p. 226.

86 Sobre la figura de estos servidores reales, con funciones habitualmente relacionadas con las armas y otros servicios a sus monarcas, tenemos una creciente bibliografía: Montero TeJadA, "Monarquía y gobierno concejil: continos reales en las ciudades castellanas a comienzos de la Edad Moderna", pp. 577590; Gamero IgeA, "Entre Castilla y Aragón. Los continos en el reinado de Fernando el Católico", pp. 193-208; y García AlCÁzAr, "Los continos reales durante la baja Edad Media. Estado de la cuestión”, pp. 335-358.

87 Archivo Duques de Medinaceli, Archivo Histórico, legajo 156, ramo 8, n. 1-6; y, especialmente, AHN, Nobleza, Osuna, C. 418, D. 43-46.

${ }^{88}$ AHN, Nobleza, Osuna, C. 418, D. 26. Escritura de fundación del mayorazgo otorgado por María Pacheco Portocarrero, condesa de Benavente, en virtud de la facultad real de los Reyes Católicos de 14 de abril de 188, a favor de su hija Beatriz Pimentel, casada con García Álvarez de Toledo. Castromocho, 28-II-1501, ante Juan Álvarez de Valladolid.

89 Delille, “Échanges matrimoniaux entre lignées alternées et système européen de l'alliance: une première approche", pp. 219-252.

90 Sobre sus futuros éxitos militares, patronazgo cultural y ascenso social, véase HernANDo SÁNCHEZ, Castilla y Nápoles en el siglo XVI. El virrey Pedro de Toledo: linaje, estado y cultura (1532-1553).

91 Real Academia de la Historia, Signatura 9/315, f. 105. Costados de doña María Pimentel y Osorio, II marquesa de Villafranca del Bierzo.
} 


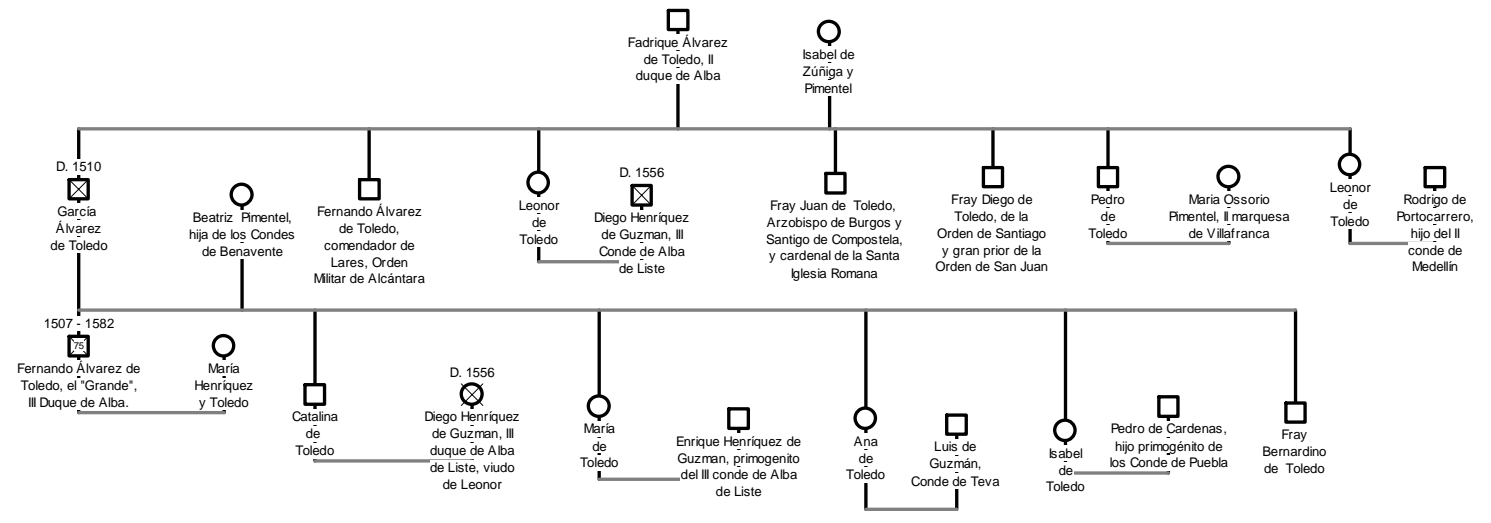

Genealogía 4. Árbol genealógico de los II duques de Alba y las dos generaciones subsiguientes. Véase página 63. 
de Toledo Osorio, hijo de Pedro y María, a partir de 1539 va a ser el III marqués de Villafranca del Bierzo. El patronímico Álvarez de Toledo, desde entonces es al que queda asociado el marquesado de Villafranca.

Y, a la vez que Jimeno nos ofrece información sobre los matrimonios, no olvida que la creación de nuevas relaciones de familia, también tiene su origen en pasados vínculos familiares desarrollados, especialmente, por los linajes Enríquez-Pimentel, y EnríquezÁlvarez de Toledo. Para poder casarse García y Beatriz es precisa bula de dispensa de consanguinidad de cuarto grado que otorga el papa Alejandro VI. También el papa Alejandro, otorga bula de dispensa de consanguinidad para el matrimonio que celebran Pedro y María, aunque en este caso por parentesco de cuarto con quinto grado ${ }^{92}$. Parentesco y alianzas políticas, por tanto, se entremezclan para hacer realidad alianzas matrimoniales en el seno de la alta aristocracia castellana. Aunque como ocurre con los grupos de poder del mundo mediterráneo, lo más frecuente es que las relaciones de parentesco y en consecuencia el grado de consanguinidad, se sitúe en el más alejado que prohíbe la Iglesia y para el que resulta factible conseguir la dispensa eclesiástica.

No es Pedro el único hijo que está a disposición de la casa, favoreciéndola con las decisiones que se toman respecto a sus vidas. Otros tres varones, como es tendencia habitual entre los grupos nobiliarios europeos según avanza el siglo $\mathrm{XVI}^{93}$, para impedir la dispersión de los bienes de la casa y la excesiva multiplicación de las ramas del árbol familiar, van a tener que permanecer solteros -el conocido fenómeno del celibato de los segundones-, aunque con una reconocida posición social. Para Fernando, Fadrique logra que los Reyes Católicos en julio de 1502 le hagan merced de la encomienda de Lares ${ }^{94}$, una de las más importante de la orden militar de Alcántara, pues contaba con unas 50.000 fanegas de tierras y, situada en Extremadura, era paso obligado para las rutas mesteñas leonesa oriental y soriana-segoviana. Los otros dos hijos célibes ingresan en instituciones eclesiásticas. Juan será arzobispo de Burgos y de Santiago de Compostela y concluirá sus días en 1557 como cardenal de la Santa Iglesia Romana. Por su parte, fray Diego de Toledo, ocupa el importantísimo beneficio de gran prior de la orden de San Juan en Castilla. Pero lo destacado es de qué manera contribuyen al engrandecimiento y consolidación de la casa de Alba. Fernando y fray Diego van a hacer circular el patrimonio de su madre, Isabel de Zúñiga, hacia su padre, al renunciar en él los bienes correspondientes a sus respectivas herencias maternas, con el fin de aumentar los recursos de la casa de Alba. E incluso Fray Diego, volviendo a poner de manifiesto cómo los parientes colaterales pueden afianzar la posición del pariente mayor de la casa, por disposición testamentaria otorgada el año 1532, propone que la "herencia que le correspondía de sus padres, la hubiese su sobrino el Gran Duque de Alba Dn Fernando"95.

\footnotetext{
ADA, C. 128, fs. 90-91 y 93.

Delille, El alcalde y el cura...., p. 303.

94 Véase sobre las presencia y actividad de la orden de Alcántara en Extremadura durante los siglos XV y XVI, los monográficos dedicados por la Revista de Estudios Extremeños, V. 64, (2008). Igualmente Palacios Martín, "La Orden de Alcántara y su incorporación a la Corona", pp. 55-74.

95 ADA, C. 128 , f. 90.
} 

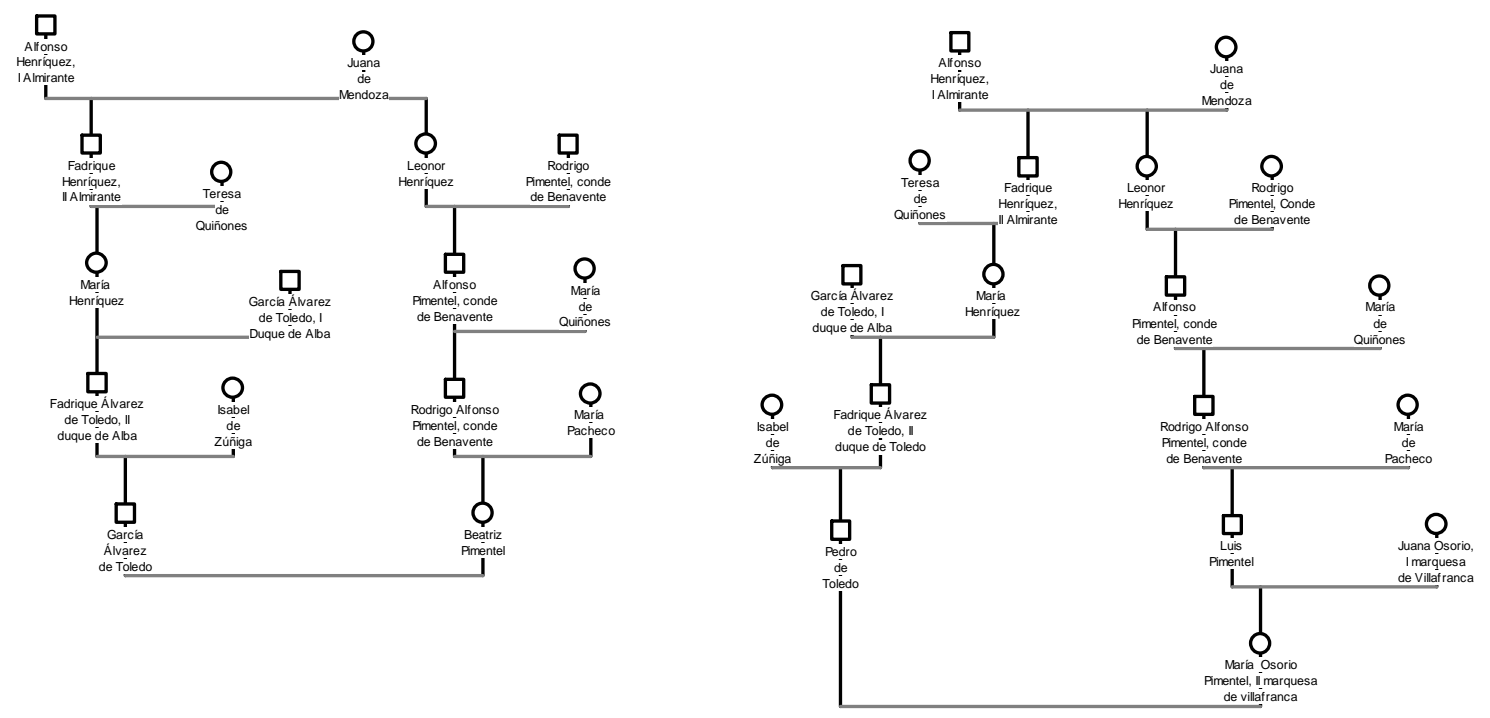

Genealogía 5. Grados de consanguinidad existentes en los matrimonios establecidos entre García Álvarez de Toledo y Beatriz Pimentel, y Pedro de Toledo y María Osorio Pimentel. Véase página 64. 
Todo el esfuerzo realizado por el II duque de Alba para dejar ordenada la sucesión de su casa y afianzada en el espectro político de Castilla, se tambalea inesperadamente. Si la guerra le había proporcionado éxitos y triunfos al segundo duque, la guerra también se lleva a su hijo primogénito, García, muerto en la "Ysla de los Gelves peleando contra los moros" -como relata Jimeno-. Su épico fallecimiento deja un enorme vacío que va cubrir Fadrique dando un salto de dos generación, es decir de abuelo a nieto, por lo que además de dedicarse a formar al hijo primogénito de García, Fernando Álvarez de Toledo y Pimentel, debe volver nuevamente a plantear una acción matrimonial que sea satisfactoria y beneficiosa para la casa.

La política matrimonial más habitual de la casa de Alba estaba determinada por sus enlaces con los Enríquez. Desde 1447 se habían establecido unas regulares relaciones matrimoniales entre ambas casas, una especie de pactos de matrimonios entre casas en el contexto de una afinidad de intereses políticos. Pero la buena relación e incluso el pacto entre las casas de Alba y de Almirante, se rompe a comienzos del siglo XVI, especialmente tras el breve reinado de Felipe $\mathrm{I}^{96}$. Pero la ruptura es con la casa del Almirante, no con el linaje de los Enríquez. La primera hija de Fadrique y Beatriz, Leonor de Toledo, casa con Diego Enríquez de Guzmán (circa 1487-1556), III conde de Alba de Liste y descendiente, a la postre, de una linaje real. A través de esta línea, repleta de vínculos familiares como lo demuestra que fuesen precisas dispensas del papa Julio II por impedimentos matrimoniales de tercer grado por un lado y de cuarto por otro ${ }^{97}$, y que no fue la vía principal en los años que Fadrique desarrolla las alianzas matrimoniales de sus hijos, en cambio sí lo va a ser cuando tiene que poner en marcha las alianzas de los hijos habidos en el matrimonio entre el fallecido y primogénito García Álvarez de Toledo y Beatriz Pimentel.

Fadrique Álvarez de Toledo al acordar y desarrollar los matrimonios de los nietos de su fallecido hijo mayor, en torno al año 1529, creemos que nos sitúa ante medidas o decisiones próximas a lo que la disciplina que estudia las reglas del parentesco, ha denominado alianzas recurrentes o circuitos matrimoniales estables, desarrollados con un fin principal: la consolidación y autoafirmación de la casa ${ }^{98}$. Aunque moralmente no bien aceptados, Fadrique encuentra en la "lógica social de los matrimonios cercanos" la solución para afianzar y dar continuidad a su casa, en unos momentos en que la nobleza nueva, ya no lo es tanto, pues se ha instalado por la gracia real, influencia políticas, relaciones sociales y medios económicos entre las casas aristocráticas más importantes de Castilla. ¿Se podía dejar en manos del azar ese logro? El viejo -andaría en torno a los 70 años- Fadrique se decide por juego de alianzas matrimoniales dentro del circuito de los parientes. Solución, a priori, de máxima garantía. Y para ello, mira

\footnotetext{
96 La amplia información que al respecto aporta ZuRITA, Los cinco libros postreros de la historia del rey Don Hernando el catholico. De la empresas y ligas de Italia, p. 104 y siguientes, ha sido magníficamente sintetizada por CALDERÓn ORTEGA, El ducado de Alba ..., pp. 125-130.

97 ADA, C. 128, fs. 87-88.

98 Lévi-Strauss, El futuro de los estudios del parentesco; Heritier, L'exercise..., pp.73-136; Zonanbend, La mémoire longue; y, especialmente, Bestard, Parentesco y Modernidad, pp. 113-168.
} 
al pasado y ve los aciertos de sus enlaces con el linaje de los Enríquez. Si ahora no es posible con la casa principal, es decir, los Almirante, si lo es con la segunda casa, con los Alba de Liste. No es difícil encontrar el medio. Toda la parentela de su hija Leonor, casada con Diego Enríquez de Guzmán, III conde de Alba de Liste, va a ser la que participe en esta alianza. Una hija de ambos, María, es la escogida para casar con su primo y futuro cabeza del linaje, Fernando Álvarez de Toledo. El propio Diego Enríquez de Guzmán, viudo ya de Leonor, vuelve a casar con una hija -Catalina de Toledo- del propio Fadrique, sin que resulte impedimento moral que Diego, como dice Jimeno es "tío por afinidad". Finalmente, el hijo primogénito de Diego y Leonor, Enrique Enríquez de Guzmán, futuro IV conde de Alba de Liste, casa con María, hija igualmente de Fadrique ${ }^{99}$.

En los tres matrimonios la proximidad del parentesco es tan fuerte, que, cuando menos, resulta preciso contar con dispensa matrimonial de segundo grado, o de segundo con tercer grado. Es la primera vez que dentro de las alianzas matrimoniales de la casa de Alba, y mostrando como se puede usar socialmente el parentesco, las relaciones abandonan la periferia de los vínculos prohibidos y se aproximaban hasta las dispensas concedidas por la Iglesia para enlaces entre parientes cercanos.

Fadrique Álvarez de Toledo fallecía el año 1531. Había dado un paso con las alianzas matrimoniales de los hijos de su hijo primogénito que sobrepasa la norma más habitual de los enlaces entre grupos de poder: ni demasiado lejos en términos sociales, ni demasiado cerca en términos de parentesco. Pero su decisión, que no podemos calificar como dice G. Delille, ni de imprevista ni de imprevisible, y que el archivero Jimeno tampoco nos puede ayudar a desvelar en qué sentido lo hace, sin embargo, si es cierto, que vista a la luz de la historia, abre el periodo más importante de la casa de Alba. Coincide con la jefatura de la misma por parte de los duques Fernando Álvarez de Toledo "el Grande" y María Enríquez y Toledo. La posición social y política conseguida a lo largo del siglo XV y los inicios del XVI, sus relaciones sociales y políticas con la Monarquía y los principales de Castilla, especialmente con el linaje Enríquez, los bienes, posesiones y riquezas acumuladas, y el acierto en las decisiones del II duque, aprovechando hasta sus máximos límites los recursos del parentesco y las alianzas matrimoniales con casas afines políticamente, dan excelentes resultados para la casa. El pequeño árbol que unos regidores toledanos comenzaron a levantar en los inicios del siglo XIII, es ahora el árbol de una de las principales casas aristocráticas de la Monarquía Hispana.

\section{Conclusiones}

Si la pretensión de este trabajo es verificar hasta qué punto alianzas matrimoniales y consanguinidad pueden ocupan un lugar central en la constitución de relaciones sociales y políticas en la nobleza castellana desde la segunda mitad del siglo XV hasta bien adentrado el siglo XVI, el análisis de la casa de Alba permite comprobar adecuadamen-

99 ADA, C. 128, fs. 96-100. 

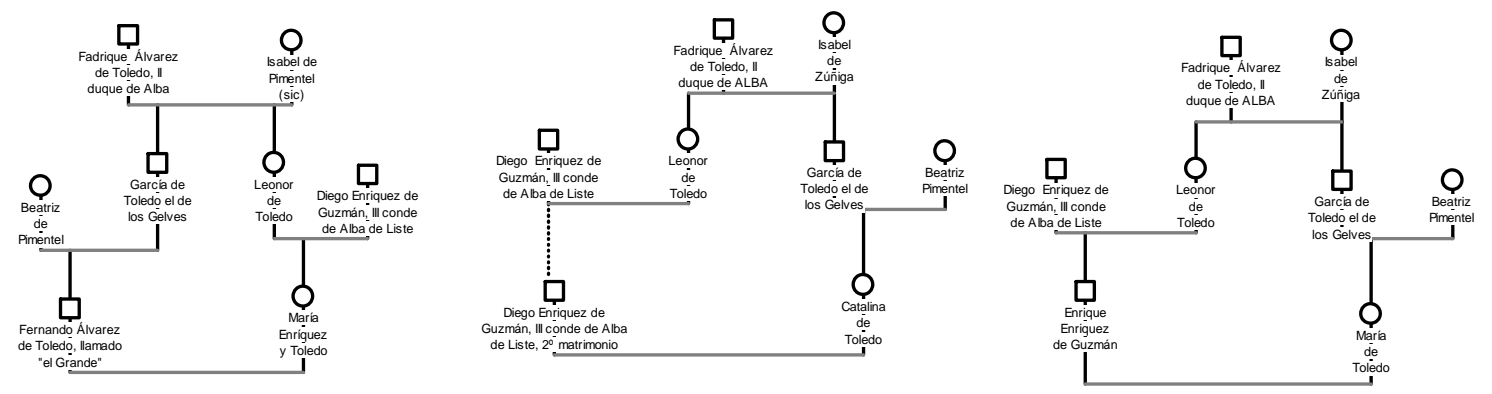

Genealogía 6. Relaciones de consanguinidad existentes en los matrimonios de los hijos de García de Toledo y Beatriz de Pimentel. Véase página 66. 
te la hipótesis de partida. No se puede postergar el importante papel de los monarcas -aún bajo la aparente debilidad de algunos Trastámaras-, y de las ligas entre nobles, pero sin lugar a dudas dentro de un sistema de parentesco bilateral como el que hay en Castilla, el matrimonio homogámico y también la consanguinidad (especialmente entre colaterales y por lo general no excesivamente cercanos en grado) es muy influyente en la consolidación de la mayor parte de la cúpula de la sociedad castellana.

Hemos intentado apartarnos de la controversia teórica alianza matrimonial versus parentesco, que durante tantos años ha gastado las fuerzas de los antropólogos. El curso de la historia, posiblemente, no admite normas estrictas y permite alternar dentro del proceso histórico hechos que son generados bien por las alianzas matrimoniales, bien por el parentesco, sin que sea preciso devenir en la fe del monodeterminismo. Lo que hemos intentado hacer es analizar, hasta qué punto los fines de familias aristocráticas orientados hacia la obtención de la máxima distinción social y el relieve político, les lleva a hacer uso indistintamente -o mejor expresado, ni previsible ni imprevisiblemente-, de las alianzas matrimoniales homogámicas, pero no encerradas en el parentesco, o bien de alianzas con parientes con los que se tienen vínculos sanguíneos próximos para lograr tanto la consolidación de su elevada posición social y política, como la de su casa.

El análisis de estas cuestiones a través de una destacada casa aristocrática castellana permite comprobar que es más la alianza que la consanguinidad la práctica que inicialmente emplean los Álvarez de Toledo. Su origen o raíz se encuentra en la oligarquía de la ciudad de Toledo y, al menos, a través de la creíble genealogía que nos aporta el archivero Jimeno, ni se remonta al ideal gótico de otras casas castellanas, ni forma parte de la vieja nobleza bajomedieval, ni tiene su origen en una sangre de gran lustre. Por esas razones, como el árbol familiar no está recargado de antigüedades, ni de parientes de nobleza inmemorial, ni de hechos de armas destacados, para ir ganando terreno socialmente resultan imprescindibles las alianzas matrimoniales a lo largo del siglo XIII y de la primera mitad del XIV. También las alianzas matrimoniales son indispensables cuando los Álvarez de Toledo comienzan a despuntar a mitad del siglo XIV y aprovechan la transformación de la nobleza que tiene lugar con la llegada de los Trastámaras a la corona de Castilla para ingresar en la nobleza nueva. En esta nueva etapa o trayectoria sociofamiliar de los Álvarez de Toledo, su ámbito político y su red de relaciones se traslada de Toledo a la Corte, o al menos al espacio de influencia que ocupan los reyes dentro la convulsa vida política de Castilla a lo largo de buena parte del siglo XV, y las alianzas matrimoniales siguen desempeñando un papel importante e incluso decisivo para apuntalarse dentro de la cúspide nobiliaria que está tallando la nobleza nueva; asimismo, es importante tanto el papel que dentro de la casa desempeñan los parientes colaterales, especialmente los tíos paternos de los parientes mayores, contribuyendo destacadamente generación tras generación a la consolidación de la casa, como el de la mujeres de la casa que transitan a otras casas, pues a través de ellas - que siguen manteniendo la calidad de parientes- se afianzan relaciones que van a ser relevantes posteriormente.

La alianza -vía matrimonial- del primer Álvarez de Toledo que consigue un título nobiliario -en lo que tiene destacada importancia el bando político por el que se inclina 
con ocasión de las ligas nobiliarias que se forman a mitad del Cuatrocientos- con una casa nobiliaria de sangre real, como son los Enríquez, va a tener una gran influencia. Ad futurum les abre las puerta para entrar en el reducido grupo que tienen el reconocimiento de grandes, a lo que sin duda contribuye igualmente sus servicios a los monarcas, que a la postre son los que otorgan la distinción; y ese atributo máximo llega hacía 1472, cuando los Álvarez de Toledo reciben el privilegio de duques -título que como había indicado unos años Juan de Mena (Tratado sobre el Título de Duque) prueba "la preeminencia e honra que es devida a la persona que tal título rescibe" 100 -. Conservar, consolidar y autoafirmar la posición social, que tiene que estar unida a una posición política, como ponen de manifiesto los servicios del I y II duque a la Monarquía de los Reyes Católicos, sigue requiriendo de alianzas matrimoniales (a veces recurriendo al doble matrimonio) efectuadas con mujeres y hombres de otras casas (Alburquerque, Osorno, Béjar y Benavente) que están muy cerca en rango social y con las que se tienen un parentesco en la periferia de los grados prohibidos por la Iglesia.

Pero, qué hacer si todo lo conseguido peligra por los destinos de la vida, por la imprevisibilidad de los accidentes biológicos, y el tronco del árbol puede verse amenazado y la sucesión de la casa en riesgos. Entonces, la experiencia acumulada, como ocurre desde 1510, obliga a replantearse acciones anteriores y situar el parentesco como la elección o estrategia más satisfactoria. Las alianzas en el seno del parentesco -nuevamente los Enríquez, aunque ahora con la rama segunda de los Alba de Liste-, mediante matrimonios recurrentes y múltiples entre parientes próximos, es la solución para conservar la troncalidad de la casa. En consecuencia, el reencadenamiento de la alianza matrimonial Álvarez de Toledo-Enríquez, en el transcurso de cuatro generaciones (1448-1529), se convierte en un sólido anclaje para la casa de Alba, a partir del cual el III duque, Fernando Álvarez de Toledo y Pimentel, el Grande, casado con María Enríquez, tanto por los méritos personales como por los servicios que presta a la Monarquía Hispánica, consolida a Alba de Tormes como una de las primeras casas aristocráticas de España.

\section{Bibliografía citada}

Agüero Carnero, Cristina, "El ocaso de los Enríquez de Cabrera. La confiscación de sus propiedades y la supresión del almirantazgo de Castilla", Tiempos Modernos, 33 (2016), pp. 132-153.

Álvarez Álvarez, César, "Los Quiñones-Condes de Luna durante la Baja Edad Media", Tierras de León: Revista de la Diputación Provincial, 44 (1981), pp. 45-60.

Álvarez Palenzuela, Vicente Ángel, "Protagonismo político de un linaje portugués en la Castilla de Juan II: Rodrigo Alfonso Pimentel", Os reinos ibéricos na Idade Média, Luis Adao da Fonseca, Luis Carlos Amaral, (coord.), ed. Civilizaçao, Oporto, V. 1, 2003, pp. 1.301-1.310.

$\overline{100}$ Mena, Tratado sobre el Título de Duque, p. 59. 


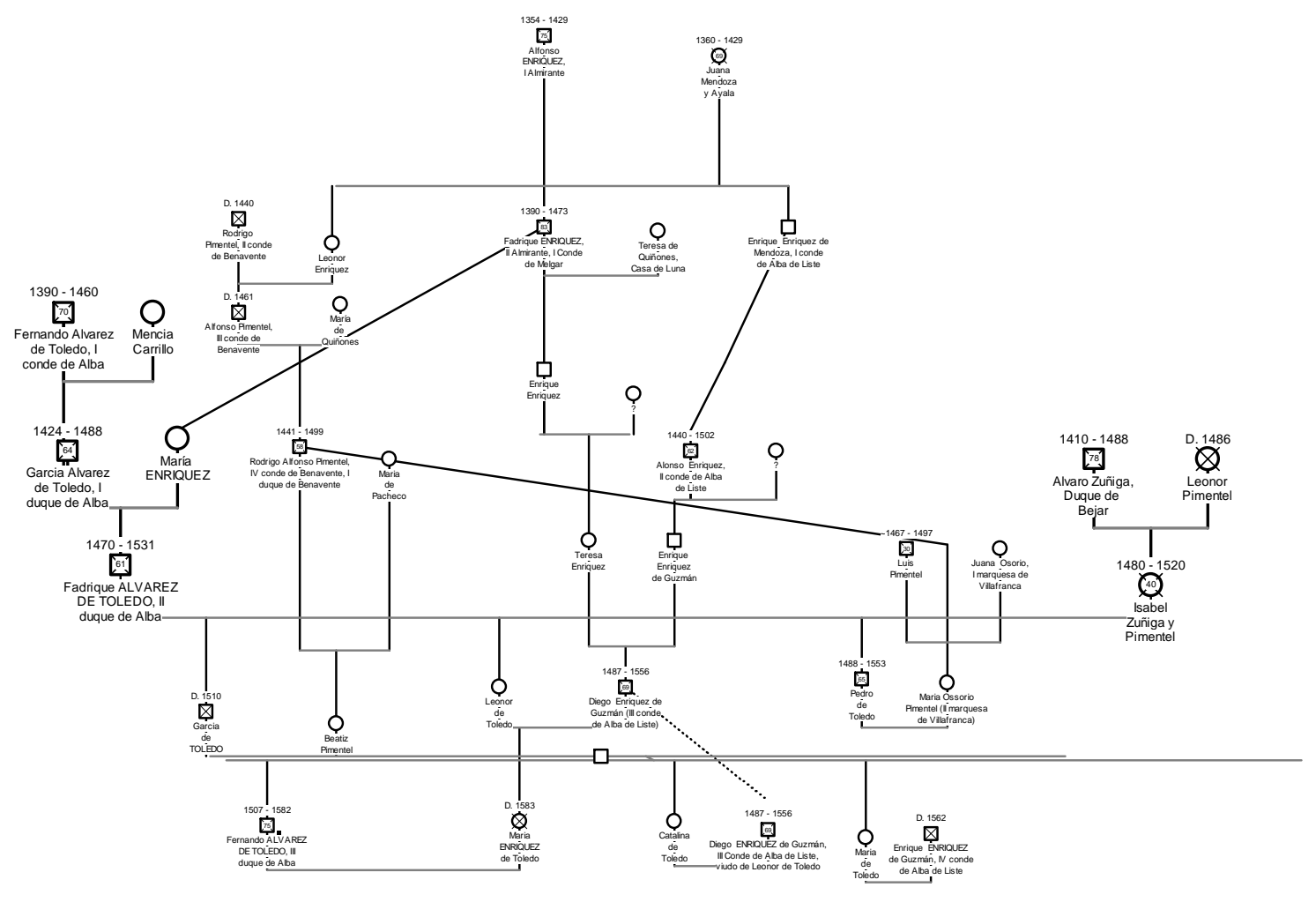

Genealogía 7. Relaciones matrimoniales entre miembros de las casas de Alba, Almirante, Alba de Liste, Benavente y Béjar (siglos XV-XVI). Véase página 68. 
Aurel, Jaume, "Memoria dinástica y mitos fundadores: la construcción social del pasado en la Edad Media", La conciencia de los antepasados. La construcción de la memoria de la nobleza en la Baja Edad Media, Arsenio Dacosta, José Ramón Prieto y José Ramón Díaz de Durana (eds,), Marcial Pons Historia, Madrid, 2014, pp. 303-334.

Ballesteros San José, Placido, Álvar Fáñez. Trayectoria histórica del defensor del reino de Toledo (1085-1114), Intermedio Ediciones, Guadalajara, 2014.

Beceiro PitA, Isabel, "La conciencia de los antepasados y la gloria del linaje en la Castilla bajomedieval", Relaciones de poder, de producción y parentesco en la Edad Media y Moderna, Reyna Pastor (comp.), CSIC, Madrid, 1990, pp. 329-350.

Beceiro Pita, Isabel, El Condado de Benavente en el siglo XV, Centro de Estudios Beneventanos "Ledo del Pozo", C.E.C.E.L.-C.S.I.C, 1998.

Beceiro Pita, Isabel, "Parentesco y alianzas políticas en Castilla (siglo XV)", Du contrat d'alliance au contrat politique: cultures et sociétés politiques dans la Péninsule Ibérique de la fin du Moyen Âge, François Foronda y Ana Isabel Carrasco (coord.), Université de Toulouse 2, Le Mirail, Toulouse, 2007, pp. 9-28.

Beceiro Pita, Isabel, "La legitimación del linaje a través de los ancestros", Memoria e historia. Utilización política en la Corona de Castilla al final de la Edad Media, Jon Andoni Fernández y José Ramón Díaz de Durana (eds.), Sílex, Madrid, 2010, pp. 77-100. Beceiro Pita, Isabel y Córdoba de la Llave, Ricardo, Parentesco, poder y mentalidad. La nobleza castellana: siglos XII-XV, CSIC, Madrid, 1990.

Bestard, Joan, Parentesco y Modernidad, Barcelona, Paidós, 1998.

Bızzochi, Roberto, Genealogie incredibile. Scritti di storia nell'Europa moderna, Il Mulino, Bologna, 2009.

BRUNNER, Otto, Terra e potere: strutture pre-statuali e pre-moderne nella storia costituzionale dell'Austria medievale, Giuffrè, Milano, 1983.

Calderón Ortega, José Manuel, "Los riesgos de la política en el siglo XV: la prisión del Conde de Alba (1448-1454)", Historia. Instituciones. Documentos, 21 (1994), pp. 41-62. CAlderón Ortega, José Manuel, El ducado de Alba. La evolución histórica, el gobierno y la hacienda de un estado señorial (siglos XIV-XVI), Dyckinson, Madrid, 2005.

Calderón Ortega, José Manuel, Felipe el Hermoso, Planeta De Agostini, Barcelona, 2008. Calderón Ortega, José Manuel, "Memoria familiar e historia de la memoria: el archivo de la Casa de Alba", Nobilitas. Estudios sobre la nobleza y lo nobiliario en la Europa moderna, Juan Hernández Franco, José Guillén Berrendero y Santiago Martínez Hernández (dir.), Doce Calles, Madrid, 2014, pp. 177-202.

Calderón Ortega, José Manuel, "El archivo de la casa de Alba", Paseo documental por el Madrid de antaño, Juan Galende Díaz, Susana Cabezas (dir.), y Nicolás Ávila (coord.), Departamento de Ciencias y Técnicas Historiográficas, Universidad Complutense de Madrid, Madrid, 2015, pp. 79-100. 
Carceller Cerviño, María del Pilar, "Nobleza cortesana, caballería y cultura: la casa ducal de Alburquerque", Títulos, grandes del reino y grandeza en la sociedad política: sus fundamentos en la Castilla Medieval, María Concepción Quintanilla Raso (dir.), Sílex, Madrid, 2006, pp. 215-263.

Carceller Cerviño, María del Pilar, "Los bandos nobiliarios y la carrera política: ascenso y privanza de Beltrán de la Cueva", Anuario de Estudios Medievales, 36-2 (2006), pp. 783-801.

Carrillo de Huete, Pedro, Crónica del Halconero de Juan II, ed. y estudio por Juan de la Mata Carriazo, Espasa-Calpe, Madrid, 1946.

Dacosta Martínez, Arsenio F., "Poderoso en parientes e rentas: conceptos, discursos y prácticas sobre el linaje en Lope García de Salazar", Studia Historica. Historia Medieval, 34 (2016), pp. 59-87

Delille, Gérard "Échanges matrimoniaux entre lignées alternées et système européen de l'alliance: une première approche", En substances. Textes pour Françoise Héritier, Paris, Fayard, 2000, pp. 219-252.

Delille, Gérard, El alcalde y el cura: poder central y poder local en el Mediterráneo occidental, siglos XV-XVIII, Universidad de Murcia, Murcia, 2015

DíAz DE DuRANA, José Ramón, "Las luchas de bandos: ligas nobiliarias y enfrentamientos banderizos en el nordeste de la corona de Castilla", XIV Semana de Estudios Medievales, Conflictos sociales, políticos e intelectuales en la España de los siglos XIV y XV, José Ignacio de la Iglesia (coord.), Instituto de Estudios Riojanos, Logroño, 2004, pp. 81-112. FERnÁNDEZ de BéTHenCourt, Francisco, Historia genealógica y heráldica de la monarquía española, Casa Real y Grandes de España, Madrid, Establecimiento Tipográfico de Jaime Rates, Tomo X, 1920.

Floristan Imizcoz, Alfredo (Coord.), 1512. Conquista e incorporación de Navarra. Historiografía, Derecho y otros procesos de integración en la Europa renacentista, Gobierno de Navarra, Pamplona, 2012.

Franco Silva, Alfonso, “Oropesa. El nacimiento del señorío toledano a fines del siglo XIV”, Anuario de Estudios Medievales, 15 (1985), pp. 299-314.

Franco Silva, Alfonso, Estudios sobre Don Beltrán de la Cueva y el ducado de Alburquerque, Universidad de Extremadura, Cáceres, 2002.

Franco Silva, Alfonso, "Las intrigas políticas de Juan Pacheco. Del combate de Olmedo a la muerte de Juan II (1445-1454)", Anuario de Estudios Medievales 37, 2 (2007), pp. 597-616. Gamero IgeA, Germán, "Entre Castilla y Aragón. Los continos en el reinado de Fernando el Católico", Poder, Fisco y Mercado en las ciudades de la Península Ibérica (siglos $X I V-X V I)$, D. Carvajal, I. Víctores, J. Añíbarro (eds.), Castilla Ediciones, Valladolid, 2016, pp. 193-208. 
García AlcÁzAr, María Francisca, "Los continos reales durante la baja Edad Media. Estado de la cuestión”, Espacio, Tiempo y Forma. Serie III, Historia Medieval, 30 (2017), pp. 335-358.

GonzÁlez Mezquita, María Luz, Oposición y Disidencia en la Guerra de Sucesión Española. El Almirante de Castilla, Junta de Castilla y León, Valladolid, 2007.

GonzÁlez SÁnchez, Rafael, "El mito gótico y la utopía de España”, La utopía en la Literatura y en la Historia, Fernando Carmona y José Miguel García (eds.), Editum, Murcia, 2008, pp. 179-196.

GonzÁlez SÁnchez, Rafael, "El mito gótico como configurador de la nación española", Europa y sus mitos, Fernando Carmona y José Miguel García (eds), Editum, Murcia, 2004, pp. 128-141.

Goody, Jack, La evolución de la familia y del matrimonio en Europa, Editorial Herder, Barcelona, 1986.

Guillén Berrendero, José Antonio, La edad de la nobleza: identidad nobiliaria en Castilla y Portugal (1556-1621), Polifemo, Madrid, 2012.

Heritier, François, L'exercice de la parenté, Seuil, Paris, 1981.

Heritier, François, Masculino/Femenino II, Fondo Cultura Económico, Buenos Aires, 2007.

Hernández Franco, Juan, "Libros de genealogías y reflexiones desde la historia social sobre los linajes castellanos en la Edad Moderna", Norba. Revista de Historia, 25 (2012), pp. 341-354.

Hernando Sánchez, Carlos José, Castilla y Nápoles en el siglo XVI. El virrey Pedro de Toledo: linaje, estado y cultura (1532-1553), Junta de Castilla y León, Salamanca, 1994. Heusch, Carlos, "Le chevalier Ferrán Mexía et son Nobiliario vero (1492): de l'imaginaire chevaleresque à la logique de l'exclusion", Atalaya, 11 | 2009, mis en ligne le 20 avril 2009, http://journals.openedition.org/atalaya/598 [15 mars 2018].

Johnson, Cristopher H., Sabean, David, Teuscher, Simon and Trivellato, Francesca, Transregional and Transnacional Families in Europe and Beyond. Experiences since the Middle Ages, Berghahn Book, New York and Oxford, 2011.

Jular Pérez-Alfaro, Cristina, "La importancia de ser antiguo. Los Velasco y su construcción genealógica", La conciencia de los antepasados. La construcción de la memoria de la nobleza en la Baja Edad Media, Arsenio Dacosta, José Ramón Prieto y José Ramón Díaz de Durana (eds.), Marcial Pons Historia, Madrid, 2014, pp. 201-236. Jular PÉrez-Alfaro, Cristina, "Porque tengo obligación: genealogía, escritura e identidad nobiliarias. Los Velasco", en Mónica Castillo Lluch y Marta López Izquierdo (eds.), Modelos latinos en la Castilla medieval, Iberoamericana/Vervuer, Madrid/Frankfurt am Main, 2010, pp. 307-330.

Klapisch-Zuber, Christiane, L'ombre des ancêtres: essai sur l'imaginaire médiéval de la parenté, Fayard, Paris, 2000. 
León Sanz, Virginia, El Archiduque Carlos y los austracistas: Guerra de Sucesión y exilio, Arpegio, San Cugat, 2014.

LÉVI-STrauss, Claude, El futuro de los estudios del parentesco, Anagrama, Barcelona, 1973. Martín Romero, José Julio, "El origen de la nobleza según el Nobiliario vero de Hernán Mexía”, Bulletin of Spanish Studies: Hispanic Studies and Research on Spain, Portugal and Latin America, 92-1 (2015), pp. 1-23.

Martin, Georges, Les jueges de Castille. Mentalités et discours historiques dans l'Espagne médievale, Publication du séminaire d'etudes medievales hispaniques de l’Université de Paris XIII, Paris, 1992.

Martínez Millán, José, La corte de Carlos V, Sociedad Estatal para la Conmemoración de los Centenarios de Felipe II y Carlos V, Madrid, 2000, T. III.

Mena, Juan de, Tratado sobre el Título de Duque, Introducción, edición y notas Louise O. Vásvari, Fainberg Tamesit Book Limited, Londres, 1976.

Molina, Bartolomé de y Herrera Maldonado, Francisco de, Breue tratado de las virtudes de don Iuan Garcia Aluarez de Toledo, Monroy, Madrid, 1621.

Monsalvo Antón, José María, "Parentesco y sistema concejil: observaciones sobre la funcionalidad política de los linajes urbanos en Castilla y León (siglos XIII-XV)", Hispania, 185 (1993), pp. 937-969.

Monsalvo Antón, José María, El sistema político concejil. El ejemplo del Señorío Medieval de Alba de Tormes y su Concejo de Villa y Tierra, Ediciones Universidad de Salamanca, Salamanca, 1988.

Monteano Sorbet, Peio J., La Guerra de Navarra (1512-1529). Crónica de la conquista española. Pamiela, Pamplona-Iruña, 2010.

Montero Tejada, Rosa María, "Monarquía y gobierno concejil: continos reales en las ciudades castellanas a comienzos de la Edad Moderna", La Administración municipal en la Edad Moderna. Actas V Reunión científica de la Asociación Española de Historia Moderna, José Manuel de Bernardo (coord.), V. 2, Cádiz, 1999, pp. 577-590.

Moreno de Vargas, Bernabé, Discursos de la nobleza de España, Biuda de Alonso Martin, Madrid, 1622.

Moreno Ollero, Antonio, Los dominios señoriales de la casa de Velasco en la baja edad media, Sanlúcar de Barrameda, Industrias Gráficas S.A., 2014.

Moxó, Salvador de, Los antiguos señoríos de Toledo, Instituto Provincial de Investigaciones y Estudios Toledanos, Toledo, 1973.

Moxó, Salvador de, "El auge de la nobleza urbana en Castilla y su proyección en el ámbito administrativo y rural a comienzos de la Baja Edad Media”, Boletín de la Real Academia de la Historia, 178-3 (1981). pp. 407-518.

Moxó, Salvador de, "Los señoríos. En torno a una problemática para el estudio del régimen señorial”, Hispania, 94 (1964), pp. 185-236. 
Moxó, Salvador de, "Los señoríos. En torno a una problemática para el estudio del régimen señorial. Conclusión”, Hispania, 95 (1964), pp. 399-430.

Nieto SoRIA, José Manuel, Un crimen en la corte: caída y ascenso de Gutierre Álvarez de Toledo, señor de Alba (1376-1446), Sílex Ediciones, Madrid, 2006.

Ortega Gato, Esteban, "Los Enríquez, Almirantes de Castilla", Publicaciones de la Institución Tello Téllez de Meneses, 70 (1999), pp. 23-65.

Palacios Martín, Bonifacio, "La Orden de Alcántara y su incorporación a la Corona”, Primeras Jornadas de Historia de las Ordenes Militares, Real Consejo de las Órdenes Militares (Fundación Lux Hispaniarum), Madrid, 1997, pp. 55-74.

Palencia Herrejón, Juan Ramón, "Elementos simbólicos del poder de la nobleza urbana en Castilla: los Ayala de Toledo al final del Medievo", En la España Medieval, 18 (1995), pp. 163-180.

PEÑA PÉRez, Francisco Javier, El surgimiento de una nación. Castilla en su historia y en sus mitos, Crítica, Barcelona, 2005.

PeÑa Pérez, Francisco Javier, "Nuño Rasura y Laín Calvo: los orígenes del pensamiento mítico sobre Castilla”, Mitificadores del pasado, falsarios de la historia, José Antonio Munita (Edt.), Universidad del País Vasco, Bilbao, 2011, pp. 33-65.

PÉREz, Mariel, "En torno a las estructuras de parentesco de la aristocracia castellanoleonesa. Revisión de los modelos interpretativos dominantes", Anales de Historia Antigua, Medieval y Moderna, 42 (2010), pp. 153-174.

PÉREZ, Mariel, "Estructuras de parentesco y poder aristocrático: la aristocracia leonesa en la alta edad media", Miscelánea Medieval Murciana, 38 (2014), pp. 213-231.

Quintanilla RAso, María Concepción, "La nobleza en la historia política castellana en la segunda mitad del siglo XV. Bases de poder y pautas de comportamiento". Actas del Congresso Internacional Bartolomeu Días e sua Época, T.1, Comissão Nacional para as Comemorações dos Descobrimentos Portugueses, Porto, 1989, pp. 181-200.

Quintanilla Raso, María Concepción, "El engrandecimiento nobiliario en la Corona de Castilla. Las claves del proceso a finales de la Edad Media", Títulos, grandes del reino y grandeza en la sociedad política: sus fundamentos en la Castilla Medieval, María Concepción Quintanilla Raso (dir.), Sílex, Madrid, 2006, pp. 17-100.

Quintanilla Raso, María Concepción y Carceller Cerviño, María del Pilar, "La construcción de la memoria de las grandes casas nobles en la Corona de Castilla. El marquesado de Priego y el ducado de Alburquerque", La conciencia de los antepasados. La construcción de la memoria de la nobleza en la Baja Edad Media, Arsenio Dacosta, José Ramón Prieto y José Ramón Díaz de Durana (eds.), Marcial Pons Historia, Madrid, 2014, pp. 271-302.

Romero Portilla, Paz, "Protagonismo del partido portugués en la política castellana del siglo XV”, Revista da Faculdade de Letras. Historia, 4 (2003), pp. 187-212.

Ruiz Domenec, José Enrique, "Sistema de parentesco y teoría de la alianza en la sociedad catalana”, en Amor, Familia y Sexualidad, Barcelona, Argot, 1984. 
Sabean, David, Kinship in Neckarhausen, 1700-1870, Cambridge University Press, Cambridge, 1998.

Sabean, David, Teuscher, Simon and Mathieu, Jon (edt.), Kinship in Europe: Approaches to the Long-Term Development (1300-1900), Berghahn Book, New York and Oxford, 2007

Sabean, David and Teuscher, Simon, "Kinship in Europe: A New Approach to LongTerm Development", en Kinship in Europe: Approaches to the Long-Term Development (1300-1900), Sabean, David, Teuscher, Simon and Mathieu, Jon (edt), Berghahn Book, New York and Oxford, 2007, pp. 1-26.

Salazar y Castro, Luis de, Índice de las glorias de la Casa Farnese, Imprenta de Francisco del Hierro, Madrid, 1726.

Soria Mesa, Enrique, La nobleza en la España Moderna, Marcial Pons, Madrid, 2007. SuÁrez Fernández, Luis, "Introducción a un linaje", Los Álvarez de Toledo. Nobleza viva, María del Pilar García Pinacho (ed.), Junta de Castilla y León, Valladolid, 1998. SuÁrez Fernández, Luis, Enrique IV de Castilla. La difamación como arma política, Ariel, Barcelona, 2001.

Torres, Margarita, "El linaje del Cid", Anales de Universidad de Alicante, Historia Medieval, 13 (2000-2002), pp. 6-49.

Torres, Margarita, Palat de Rey: el Palacio de los Quiñones, Condes de Luna y su entorno urbano palatino, Servicio de Publicaciones Universidad de León, León, 2008. VAL VAldiviEso, María Isabel del, "Los bandos nobiliarios durante el reinado de Enrique IV”, Hispania, 130 (1975), pp. 249-294.

Valverde Ogallar, Pedro Blas, Manuscritos y heráldica en el tránsito a la modernidad: el libro de armería de Diego Hernández de Mendoza, Universidad Complutense, Servicio de Publicaciones, Madrid, 2005.

Villa Prieto, Josué, "La escritura de la Historia en la Baja Edad Media: deseo racional vs. propaganda política. La mentalidad de los cronistas", Historiografías, 10 (2015), pp. 65-84.

Zonanbend, Françoise, La mémoire longue, PUF, Paris, 1981.

Zurita, Jerónimo, Los cinco libros postreros de la historia del rey Don Hernando el catholico. De la empresas y ligas de Italia, Zaragoza, Diego Dormer, 1670.

Zurita, Jerónimo Historia del Rey Don Hernando el Catolico, de las empresas y ligas de Italia, T. 5, Pedro Lanaja, Zaragoza, 1690. 